\title{
WestVirginiaUniversity
}

THE RESEARCH REPOSITORY @ WVU

Graduate Theses, Dissertations, and Problem Reports

2011

\section{Spatial Features of Okun's Law Using U.S. Data}

\author{
Casto Martin Montero Kuscevic \\ West Virginia University
}

Follow this and additional works at: https://researchrepository.wvu.edu/etd

\section{Recommended Citation}

Montero Kuscevic, Casto Martin, "Spatial Features of Okun's Law Using U.S. Data" (2011). Graduate Theses, Dissertations, and Problem Reports. 3386.

https://researchrepository.wvu.edu/etd/3386

This Dissertation is protected by copyright and/or related rights. It has been brought to you by the The Research Repository @ WVU with permission from the rights-holder(s). You are free to use this Dissertation in any way that is permitted by the copyright and related rights legislation that applies to your use. For other uses you must obtain permission from the rights-holder(s) directly, unless additional rights are indicated by a Creative Commons license in the record and/ or on the work itself. This Dissertation has been accepted for inclusion in WVU Graduate Theses, Dissertations, and Problem Reports collection by an authorized administrator of The Research Repository @ WVU.

For more information, please contact researchrepository@mail.wvu.edu. 
Spatial Features of Okun's Law Using U.S. Data

\author{
Casto Martin Montero Kuscevic \\ Dissertation submitted to the \\ College of Business and Economics \\ at West Virginia University in partial \\ fulfillment of the requirements for the degree of
}

Doctor of Philosophy

in

Economics

\author{
Arabinda Basistha, Ph.D. (Chair) \\ George Hammond, Ph.D. \\ Peter Schaeffer, Ph.D. \\ Stratford Douglas, Ph.D. \\ Donald Lacombe, Ph.D.
}

Keywords: Okun's Law; Regional Unemployment; Spatial Spillovers; Forecasting Model; Panel Data 


\section{Abstract \\ Spatial Features of Okun's Law Using U.S. Data}

\section{Casto Martin Montero Kuscevic}

This dissertation addresses issues related to the regional labor market interactions within the United States using the Okun's Law as theoretical framework. In chapter one I estimate the state-level Okun's law after accounting for national changes and spatial spillovers. The estimates show that state-specific growth has a small effect on state unemployment rate changes. State growth experiences that are part of national or regional growths have a substantially bigger effect on state unemployment rates. I compare my results with international data which show a much larger association after accounting for time effects and spatial spillovers; implying that uncoordinated state-level demand management policies may not have substantial effects on unemployment rates in an integrated labor market. In chapter two I use 358 Metropolitan Statistical Areas (MSA) during the period 2002-2009 to examine the relationship between the change in the unemployment rate and output growth. My main finding is that urban unemployment rate is highly dependent on national and regional conditions, implying the existence of a national labor market rather than urban labor markets. State level data shows a similar pattern, although their dependence on national conditions is lower compared with Metropolitan Statistical Areas. Finally chapter three uses pooled data and several linear models, to compare the out-of-sample forecast performance for the unemployment rate for 48 U.S. states; using the root mean square forecast error RMSFE to choose the best model. I also run different tests to select between the best candidates. My research shows that the predictive accuracy of the forecast improves when spatially weighted variables are included. I also found that an AR(1) with a spatial autoregressive lag seems to be the best model in terms of a lower RMSFE; results also moves toward keeping the parsimony of the model. 


\section{Dedication}

I want to dedicate this project to my best professors in the School of Life: Guillermo and MaryLuz.

A special mention to Guiller, Carolina and Mariela my awesome classmates in "How to Support Each Other 101” 


\section{Acknowledgements}

My sincere and deepest gratitude to my dissertation advisor Dr. Arabinda Basistha for his patience, guidance, support and most importantly his friendship during these five years at WVU. I would also like to thank my committee members Dr. Stratford Douglas, Dr. George Hammond, Dr. Donald Lacombe and Dr. Peter Schaeffer for all their comments, suggestion and advice which have greatly improved my dissertation. 


\section{Table of Contents}

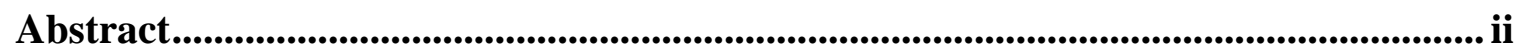

Acknowledgements .................................................................................................................... iv

List of Tables ............................................................................................................................ vii

Purpose and Agenda .............................................................................................................. 1

The Role of National Changes and Spatial Spillovers in State-Level Okun's Law .... 3

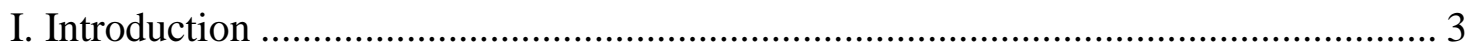

II. The Data and the Model Specifications ……………............................................. 6

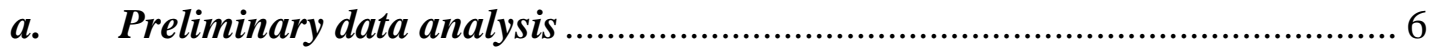

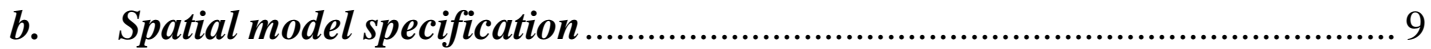

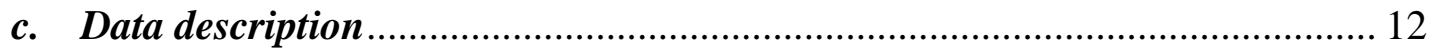

III. Estimation Results from Full Sample ………….............................................. 12

IV. Estimation Results from the Sub-sample 1987 - 2009 ..................................... 15

V. Estimation Results from 10 Industrialized Countries ............................................ 16

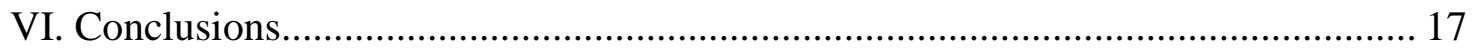

Okun's Law and Urban Spillovers...................................................................................... 28

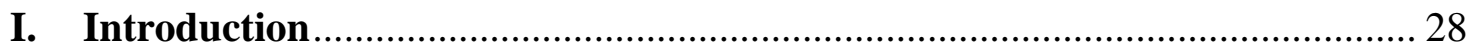

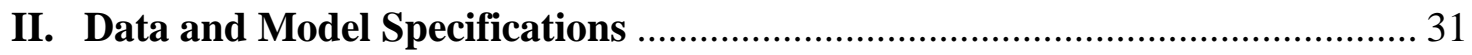

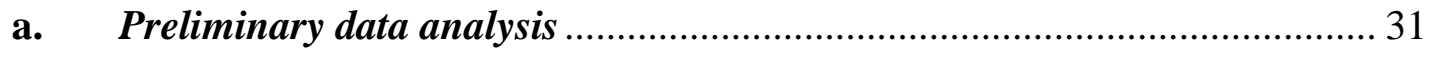

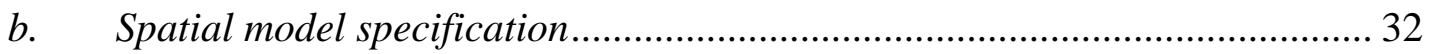

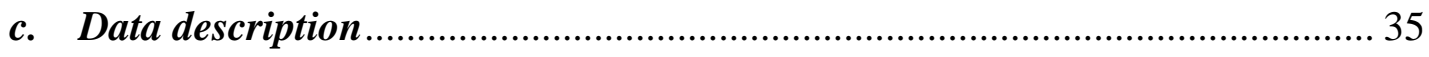

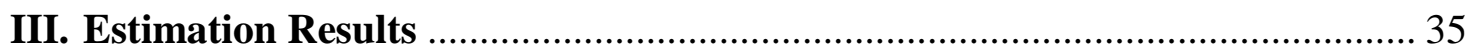

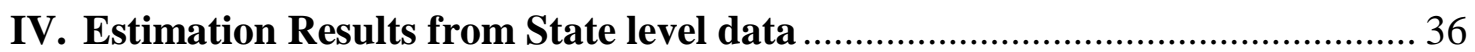

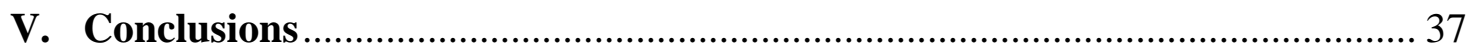

Forecasting U.S. State Unemployment: Role of Spatial Spillovers ............................... 47

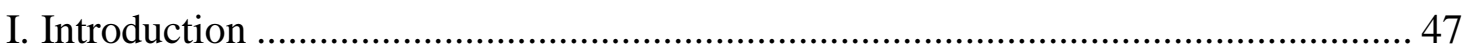

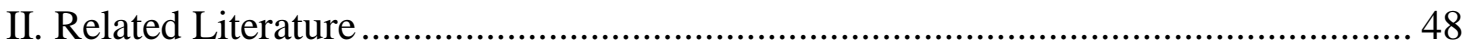

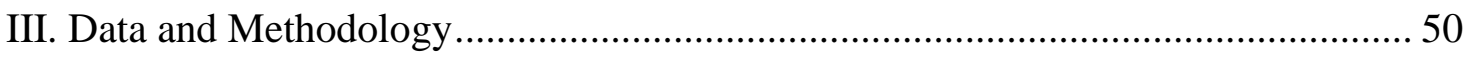

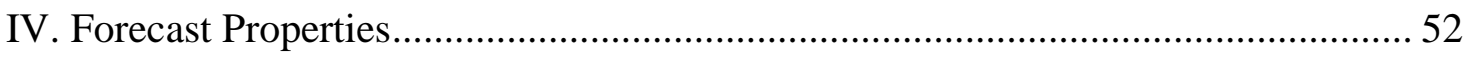

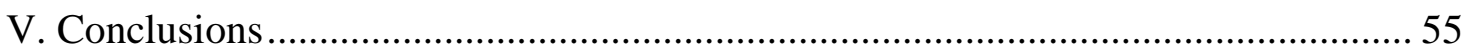

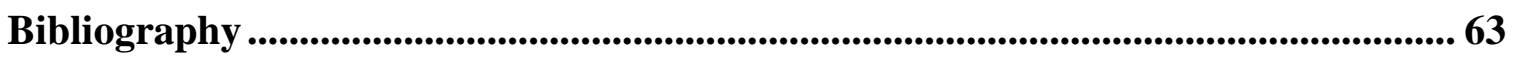

Appendix...................................................................................................................................... 68 


\section{List of Figures}

Figure 2.1 Examples of Comovement in the Unemployment Rates of Neighboring States 24

Figure 2.2 Moran's I Coefficient for States for the Period 1978-2009........................... 25

Figure 3.1 Moran's I for MSA's for the Periodd 2002-2009......................................... 45 


\section{List of Tables}

Table 2.1: National and State-level Estimates of Okun's Law ..................................... 19

Table 2.2: Panel Estimates of Okun's Law without Spatial Effects .............................. 19

Table 2.3: Panel Estimates of Okun's Law with Spatial GDP Spillovers ....................... 20

Table 2.4: Panel Estimates of Okun's Law from Spatial Durbin Model ......................... 20

Table 2.5: Panel Estimates of Okun's Law without Spatial Effects, 1987 - 2009........... 21

Table 2.6: Panel Estimates of Okun's Law with Spatial GDP Spillovers, 1987 - 2009 ... 21

Table 2.7: Panel Estimates of Okun's Law from Spatial Durbin Model, 1987 - 2009.... 22

Table 2.8: International Panel Estimates of Okun's Law without Spatial Effects........... 22

Table 2.9: International Panel Estimates of Okun's Law with Spatial GDP Spillovers ... 23

Table 2.10: International Panel Estimates of Okun's Law from Spatial Durbin Model... 23

Table A.2.1: Panel Estimates of Okun's Law from Spatial Autoregressive Model ........ 26

Table A.2.2: Panel Estimates of Okun's Law from Spatial Autoregressive Model, 1987-

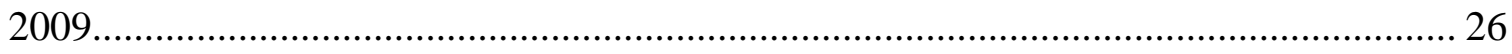

Table A.2.3: Panel Estimates of Okun's Law from Spatial Durbin Model Using Gaps .. 27

Table 3.1: Panel Estimates of Okun's Law without Spatial Effects ............................... 39

Table 3.2: Panel Estimates of Okun's Law with Spatial GDP Spillovers. ...................... 39

Table 3.3: Panel Estimates of Okun's Law from Spatial Durbin Model. ........................ 40

Table 3.4: Panel Estimates of Okun's Law with Spatial GDP Spillovers. ...................... 40

Table 3.5: Panel Estimates of Okun's Law from Spatial Durbin Model. ......................... 41

Table 3.6: Panel Estimates of Okun's Law without Spatial Effects. .............................. 41

Table 3.7: Panel Estimates of Okun's Law with Spatial GDP Spillovers. ...................... 42

Table 3.8: Panel Estimates of Okun's Law from Spatial Durbin Model. ........................ 42

Table 3.9: Panel Estimates of Okun's Law with Spatial GDP Spillovers. ...................... 43

Table 3.10: Panel Estimates of Okun's Law from Spatial Durbin Model....................... 43

Table A.3.1: Panel Estimates of Okun's Law from Spatial Autoregressive Model. MSA's

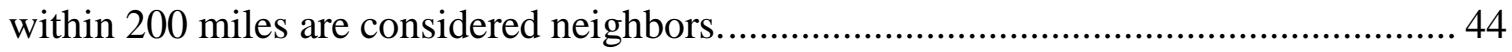

Table A.3.2: Panel Estimates of Okun's Law from Spatial Autoregressive Model. Weight

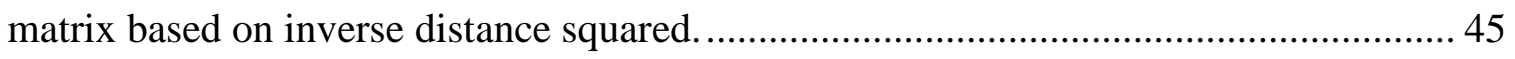

Table 4.1: Models without national GDP as an independent variable ............................ 57 
Table 4.2: Root mean square forecast error without controlling for national GDP......... 58

Table 4.3: Root mean square forecast error controlling for national GDP .....................59

Table 4.4: Clark-West test for models four and one without controlling for national GDP

Table 4.5: Clark-West test for models four and ten controlling for national GDP........... 61 Table 4.6: Clark-West test for models four with and without controlling for national GDP 


\section{Chapter 1}

\section{Purpose and Agenda}

Unemployment is without doubt one of the most important macroeconomic variables; it has inspired heated theoretical and empirical debates and different streams of economics try to explain its behavior and the forces behind it. Interesting enough is the fact that is very popular in non-academic circles. The popular media for instance exhibit news on unemployment every day, the reason may be that in one way or another every single person is concerned and affected about unemployment -or employment- and this becomes even more evident in periods of economic downturn where unemployment rate can even reach the two digits.

The high popularity of unemployment among non-academic and the popular media has an impact on its own mainly on policy makers and politicians, because ultimately they -and not necessarily economists- have the power to choose a policy that can affect -either for good or for bad- the behavior of unemployment.

At this point it worth mentioning that the revolution in transportation and communications have changed our view about distances, this mean that people can move almost costless from one place to another. To be more specific, agents can move at a very low cost in order to get a job, by the same token they can live in one place and work in another or relocate very easily to a different place. For this reason-among others- we 
will look at unemployment from a spatial perspective at different aggregation levels and with a different set of spatial techniques. It will become clear that the aim of this work is to expand the existing literature on the behavior of unemployment such that could be useful for policy purposes.

This dissertation is divided into three independent chapters. Chapter one examines how the relationship at state level between the unemployment rate and the gross domestic product -known as the Okun's Law- changes when we include spatial spillovers on both variables. Our result suggests that state's demand driven policies to decrease unemployment may lead to unexpected results if spillovers from neighboring states are not included.

Chapter two uses a similar methodology as chapter one but the aggregation level is different. We now look at 358 Metropolitan Statistical Areas and compare this result with those obtained at a state level. Our results are consistent with the theory in the sense that a higher aggregation level usually means a lower spatial dependence.

Finally chapter three shed light in the problem of choosing a good variable to forecast unemployment. Our results show that the models that used spatially weighted unemployment as an explanatory variable produce a better forecast than those that used the more traditional autoregressive model or any variation of it.

As mentioned in the beginning of this introduction, the literature on unemployment is very rich and in many topics still inconclusive, this creates a niche for researches, niche that we took advantage of. We do not pretend to say that our results are conclusive; however we strongly believe that this dissertation is a step forward in the study of the behavior of unemployment. Particularly we believe that is a contribution for policy makers interested in looking at the behavior of unemployment in a spatial context. 


\section{Chapter 2}

\section{The Role of National Changes and Spatial Spillovers in State- Level Okun's Law}

\section{Introduction}

Low unemployment rate is an important goal for macro policymakers. The crucial empirical link between output and unemployment is provided by Okun's Law, introduced in Okun (1962) ${ }^{1}$. A large number of empirical studies and informal estimates show that a 1 percentage point reduction in the unemployment rate is generally associated with a two to three percent rise in real GDP ${ }^{2}$. Kaufman (1988) and Moosa (1997) estimated and compared Okun's Law for industrialized economies showing that the unemployment response to GDP fluctuations in other countries is generally lower than in the U.S. Even though Okun's Law is primarily a statistical relationship, Gordon (1984), Prachowny (1993), Attfield and Silverstone (1997) provided the microfoundations for this relationship based on production function approaches.

Regional estimates of Okun's Law report fairly large and negative associations. Blackley (1991) used time series data on 26 US states individually to analyze the issue. The average estimates confirmed the national level result that 3.1 percent GDP increase

\footnotetext{
${ }^{1}$ Humphrey-Hawkins Act of 1978 assumes the unemployment rate consistent with full employment is 4 percent; same as Okun (1962).

${ }^{2}$ Due to space considerations, we do not attempt to provide a comprehensive list of the issues and studies on this topic. Weber (1995) stresses the sensitivity of this coefficient to model specifications and econometric techniques. Knotek (2007), Gordon (2010) reviews the recent issues from a national perspective. Neely (2010) provides a great example of recent informal estimates of Okun's coefficient from six industrialized countries.
} 
reduces the unemployment rate by 1 percent. The differences in the Okun's coefficients were associated with age and gender of the labor force and tax policies at the state level. Freeman (2000) found little difference in the U.S. regional estimates of Okun's Law. Adanu (2005) estimated and compared the Okun's coefficient for the 10 provinces of Canada. They ranged from 2.1 to 1.0 ; the higher responses of unemployment to changes in real GDP were mainly from the industrialized provinces. Christopoulos (2004) analyzed Greek regional data confirming the negative relationship for six out of 13 regions. Villaverde and Maza (2009) reported large and negative estimates for almost all the regions of Spain. Very few of the regional studies use formal spatial econometric techniques to estimate Okun's Law. Kosfeld and Dreger (2006) analyzed the German labor market using spatial techniques. Yazgan and Yilmazkuday (2009) provided evidence favoring spatial convergence of the Okun's coefficient over time within the US.

The idea to analyze the behavior of regional Okun's Law stem from the observed regional unemployment rate differentials and its underlying adjustment mechanism. It has been widely documented that variables such as differences in amenities, relative wages, and market potential are responsible for disparities in the regional unemployment rate. Elhorst (2000) notes that these differences can lead to a stable equilibrium in regional unemployment rate differentials. Deviations from this equilibrium due to demand shocks generate imbalances in the relative unemployment rate among regions. Three adjustment mechanism can operate through wage, labor mobility, and relocation of firms. Blanchard and Katz (1992) suggested labor migration as the predominant mechanism to reach back to the equilibrium. Molho (1995) moved a step forward using spatial econometric to test if the adjustment to local demand shocks can be captured as a spatial autocorrelation process. The author found significant spatial interactions in unemployment following a 
demand shock. The author identifies labor migration and commuting as the primary reasons for observed spatial dependence in regional unemployment.

We start out by noting that state level estimates of Okun's Law are generally lower than the national estimates in the US; although still quantitatively large as reported in the previous research. We argue that state-specific economic growth affects the unemployment rate differently than the national growth or regional growth experiences in an integrated labor market. We estimate the state-level Okun's law after accounting for national time effects and spatial spillovers in a panel dataset. The estimates show that state-specific growth has a small effect on state unemployment rate changes. State growth experiences that are part of national or regional growths have a substantially bigger effect on state unemployment rates.

Additionally, a subsample analysis of the post 1986 period confirmed the above results. Model selection showed that the state unemployment rate changes are best modeled as a spatial Durbin model that allows for both neighborhood GDP spillovers and spatial autoregression. International data from ten industrial countries show a much larger association after accounting for time effects and spatial spillovers. Overall, the results imply that uncoordinated state-level demand management policies may not have substantial effects on unemployment rates in an integrated labor market.

In the next section, section II, we perform some preliminary data analysis, lay out the formal spatial models, and describe in detail the data and the estimation techniques. In Section III we discuss the estimation results for the full sample and their interpretations. In section IV we conduct a sub-sample analysis of the data. In section $\mathrm{V}$ we compare our results with international data. Finally, we conclude in section VI. 


\section{The Data and the Model Specifications}

\section{a. Preliminary data analysis}

We start our analysis by illustrating three issues that require special attention. The first issue is comparison of the national results with the state-level results. The basic differenced version of Okun's law that we use is the following equation ${ }^{3}$ :

1. $\Delta U_{t}=\beta_{1}+\beta_{2} \Delta g d p_{t}+\varepsilon_{t}$

where $\Delta U$ is the change in unemployment rate, $\Delta g d p$ is the change in the natural log of real GDP, $t$ is a time index where $t=1 \ldots T$, and $\varepsilon$ represents the error term $\left(\varepsilon \sim \mathrm{N}\left(0, \sigma^{2}\right)\right)$. Okun's coefficient is calculated as $\frac{-1}{\beta_{2}}$; we use a minus sign because we expect $\beta_{2}$ to be negative. The estimate of $\beta_{2}$ for the US national sample from 1978 to 2009 using annual data is -0.45 as reported in Table 2.1. However, when we repeat the exercise individually for 48 contiguous states, the average estimate is -0.26 ; lower than the national estimate ${ }^{4}$.

When we extend this to a panel data set, the basic model is adjusted to account for state-specific fixed effects as follows:

2. $\Delta U_{i, t}=\beta_{1}+\beta_{i}+\beta_{2} \Delta g d p_{i, t}+\varepsilon_{i, t}$

The results for this model are in the first two columns of Table 2.2. The first column does not consider state-specific fixed effects. Both estimates are close to -0.2. Both numbers are lower than the national data estimates reported in Table 2.1 suggesting that national economic growth has different effect on unemployment rates than the state-level growth.

\footnotetext{
${ }^{3}$ The main alternative to this specification is the output gap version. The comparable references for US state level analysis are Blackley (1991) and Yazgan and Yalmazkuday (2009). Both use the differenced version. The empirical results of the gap version are available on request.

${ }^{4}$ Villeverde and Maza (2009) estimates for the regions of Spain have the same feature for all three types of gap measurement in their Table 1. However, they do not discuss this property in the study.
} 
Based on these estimates, we will augment our panel data model to explicitly consider the national changes.

The second issue is to allow for the national changes in the panel data model. We have two alternatives. The first alternative is to introduce national growth explicitly in the model. The basic panel model from equation 2 is adjusted to allow for national growth as follows:

3. $\Delta U_{i, t}=\beta_{1}+\beta_{i}+\beta_{n} \Delta g d p_{t}^{n}+\beta_{2} \Delta g d p_{i, t}+\varepsilon_{i, t}$

Where $\Delta g d p^{n}$ the national real GDP growth rate. The second alternative is to allow for time effects as follows:

4. $\Delta U_{i, t}=\beta_{1}+\beta_{i}+\beta_{t}+\beta_{2} \Delta g d p_{i, t}+\varepsilon_{i, t}$

where $\beta_{i}$ accounts for state specific fixed effects and $\beta_{t}$ accounts for time effects.

In the third column of Table 2.2, we show the estimates of equation 3 . The sum of the coefficients of GDP growth and national growth adds up to -0.41 ; fairly close to the national estimates of -0.45 . This implies that the disparity between national and statelevel results stem from the state growth experiences that are not part of national growth experiences. In the fourth column of Table 2.2, we show the estimates of equation 4 that account for national movements in the unemployment rate changes beyond national output growth. The coefficient of state GDP growth is very similar to the one reported in the previous column. But, Akaike's (1974) information criterion (hereafter AIC) favors the time effects model quite strongly. Therefore, we will use the time effects model for our analysis.

Our third consideration is modeling spatial spillovers between the states. We begin with an informal example of spatial dependence in state level unemployment data. 
In the top panel of Figure 2.1, we show the annual unemployment rate changes in Illinois and Indiana from 1978 to 2009 after subtracting the yearly average unemployment rate changes of the 48 contiguous states. The correlation between the two series of the two neighbors is 0.44 . Similarly, in the data shown in the bottom panel of Figure 2.1, the correlation between Ohio and Pennsylvania is 0.34 . This shows that there could be spatial dependence in the unemployment rate changes of the states beyond the common national changes.

We explore this issue further by regressing each state's unemployment rate changes less the national average changes on its GDP growth rates less the national average. The residuals of Indiana and Illinois have a positive correlation of 0.27 . The residuals of Ohio and Pennsylvania have a correlation of 0.25 , while the correlation of the residuals of Ohio and Indiana is 0.43 . Finally we obtained the residuals from equation one and calculated the Moran`s I coefficient for each year. The Moran’s I coefficient is a measure of spatial autocorrelation; it also allows us to test the null hypothesis of spatial independence; even though some authors have pointed out that this test is not a proper statistical test because does not consider an explicit alternative hypothesis (Arbia 2006), however we think that for this initial exploratory phase of the data the Moran's I coefficient gives us a panoramic view that let us infer how the data behaves. Still we overcome the problem of no alternative hypothesis later by using a Lagrange Multiplier test (LM). As shown in figure 2.2 with only one exception for the year 1997 all the Moran's I coefficients are positive, furthermore most of them lay above 0.2 and about one third lay above 0.4. All of these informal empirics suggest that there could be quantitatively important spatial dependence in the state level unemployment rate that should be accounted for while modeling Okun's Law. 


\section{b. Spatial model specification}

We extend equation 4 to allow for spatial dependence by specifying the Panel Spatial Durbin Model (hereafter PSDM):

5. $\Delta U_{i, t}=\beta_{1}+\beta_{i}+\beta_{t}+\beta_{2} \Delta g d p_{i, t}+\theta \sum_{j=1}^{N} w_{i, j} \Delta g d p_{j, t}+\rho \sum_{j=1}^{N} w_{i, j} \Delta U_{j, t}+\varepsilon_{i, t}$

where $i=1 \ldots N, \varepsilon$ represents the idiosyncratic term $\left(\varepsilon \sim \operatorname{MVN}\left(0, \sigma^{2} I_{n}\right)\right), \rho$ measures the

spatial dependence in the dependent variable. Finally, $\sum_{j=1}^{N} w_{i, j} \Delta g d p_{j, t}$ and $\sum_{j=1}^{N} w_{i, j} \Delta U_{j, t}$

are the spatial feedbacks of real GDP growth and change in unemployment rate. They are the weighted average of the values of real GDP growth and change in unemployment rate for the neighbors of state $\mathrm{i}$. To model the spatial spillovers, we use a $48 \times 48$ matrix of first order queen spatial contiguity matrix W. This matrix contains either one or zero depending on whether or not states share a common border. So, the element $w_{i, j}$ of this matrix is one if and only if state $\mathrm{i}$ is a neighbor of state $\mathrm{j}$, and is zero otherwise. There are two characteristics of this matrix: the main diagonal is composed of only zeros (since a state cannot be its own neighbor) and the entire matrix is normalized in such a way that the individual rows sum up to one. Given that the rows add up to one all the neighbors of a given state have the same spatial weight (i.e. if there are 5 neighbors of a given state, each will have a weight of 0.2 ).

In the PSDM specified in equation 5, we allow for a spatial lag of GDP growth and a spatial lag of the dependent variable. Two special cases are worth mentioning. If the coefficient $\rho$ is restricted to zero, we have a panel SLX model. If $\theta$ is restricted to zero, we have a panel spatial autoregessive model (SAR). If we restrict both coefficients 
to zero, we get back the simple panel model described in equation 4 . We use the AIC to compare between empirical performances of the different model specifications.

Econometrically, omission of spatial variables in a spatially dependent data leads to biased least squares estimates. There are multiple economic reasons for modeling spatial spillovers in this case. Large metropolitan statistical areas with common labor market often encompass multiple states. As a result, a rise in GDP growth of one state can reduce unemployment rates of the neighboring state. Similarly, unemployment rates vary considerably with socio-demographic patterns and neighboring states often share similar socio-demographic properties. Finally, as LeSage and Pace (2009) show, unobserved common properties between spatial neighbors that are associated with other explanatory variables can be modeled as a spatial Durbin model.

Before estimating the PSDM, we feel it is necessary to discuss the interpretation of our empirical output; especially the direct effect and the indirect effect in the context of spatial autoregressive and spatial Durbin models. Recently, LaSage and Dominguez (2010) lucidly explained this issue in the context of the public choice literature. They stressed that the coefficient of an explanatory variable from least squares and the coefficient of the same variable from spatial models with an autoregressive lag should not be compared. Instead, one should use the 'direct' effect of that variable in spatially dependent models.

One can illustrate this issue by rewriting equation 5 in matrix notation:

6. $Y=\Psi+\Gamma+X \beta+W_{T} X \theta+W_{T} Y \rho+\varepsilon$

where $Y=\Delta U, X=\Delta G D P$ and $W_{T}=I_{T} \otimes W . \Psi$ and $\Gamma$ are vectors of state and time fixed effects respectively. As before, $\mathrm{W}$ is the $\mathrm{N} \times \mathrm{N}$ spatial weight matrix. We note that 
$Y$ is in both sides of equation 6 , therefore we can rewrite it and obtain the data generation process as:

7. $Y=Z^{-1}\left(\Psi+\Gamma+X \beta+W_{T} X \theta+\varepsilon\right)$

where $\mathrm{Z}$ is an $\mathrm{NT} \times \mathrm{NT}$ matrix equal to $\left(I_{N}-\rho W\right)$ in the main diagonal and zero elsewhere ${ }^{5}$. The marginal effect on $\mathrm{Y}$ of a change in $\mathrm{X}$ is given by $\left(I_{N}-\rho W\right)^{-1}\left(I_{N} \beta_{k}+W \theta_{k}\right)$. The left hand side of the expression can be expanded as $\left(I_{N}-\rho W\right)^{-1}=\left(I_{N}+\rho W+\rho^{2} W^{2}+\rho^{3} W^{3}+\ldots\right)$. This infinite expansion shows that for the PSDM each $y_{i t}$ not only depends on the values of the independent variable but also on a combination of values of neighboring states scaled by $\rho$ as well as higher-order neighbors.

In the above context, the direct effect can be interpreted as the change in the dependent variable of state $i$ due to a one unit change in the independent variable of state i. Mathematically it is the average of the diagonal elements of $\left(I_{N}-\rho W\right)^{-1}\left(I_{N} \beta_{k}+W \theta_{k}\right)$. However, the change in the independent variable of state $\mathrm{i}$ affects other states too, a feature not present in standard least squares models. The cumulative effect of the change in the independent variable of state $\mathrm{i}$ on other states is termed as the indirect effect or the spillover effect. The indirect effect can be calculated by subtracting the direct effect from the total effect. The total effect is the average of the sum of the rows of $\left(I_{N}-\rho W\right)^{-1}\left(I_{N} \beta_{k}+W \theta_{k}\right)$.

The type of panel data we are analyzing adds another issue to be considered. A lot of the variation in the dependent variable is common to all the states in the sample. We

\footnotetext{
${ }^{5}$ The full derivation is in the appendix at the end.
} 
term it as the 'national' effects. Ignoring this feature will bias the estimates of actual spatial spillover present in the data. We capture this by using the time effects in the panel data. Model comparisons using AIC can show the empirical importance of this effect.

\section{c. Data description}

The annual data for 48 contiguous states of the United States over the period 1977-2009 was obtained from Bureau of Economic Analysis and Bureau of Labor Statistics. We do not consider Alaska and Hawaii. We used the growth in quantity indexes to compute real GDP growth. Three issues are worth discussing at this point. One, the Bureau of Economic Analysis does not recommend merging the entire data on real GDP given a change in the methodology to measure GDP that took place in 1998. However, subsample analysis that divides our sample between pre 1998 and post 1998 do not alter our results. Moreover, we ran a panel Chow test and we could not reject the null of no structural break for the year 1998. The results we present in this study are based on the entire data set. Two, we conducted LM tests to examine whether a spatial error model is more appropriate. The tests strongly favored the spatial Durbin model. Three, we use maximum likelihood procedures to estimate the PSDM since the least squares estimates will be biased ${ }^{6}$.

\section{Estimation Results from Full Sample}

In Table 2.3 we present the results for the SLX model that includes a spatial lag of GDP growth, our first and simplest spatial model. The first column shows the estimates with no fixed effects, the second column shows the estimates with state fixed effects and

\footnotetext{
${ }^{6}$ The MATLAB codes to solve panel SAR models and PSDM by Paul Elhorst can be found at http://www.regroningen.nl/index_en.html
} 
the third column presents the estimates with both state fixed effects and time effects. We follow this format for Table 2.4 as well. We observe that all the spatial GDP coefficient estimates are negative and significantly different from zero at the five percent level. Two things are worth noting in this table. One, the effects of the spatially weighted GDP growth variable are more than double the effects of own GDP growth on unemployment changes when time effects are not included. This shows the importance of modeling spatial effects in our dataset. Two, AIC favors the time effects model.

When we include time effects, the effect of spatially weighted GDP growth is only marginally larger than the own GDP growth effect. This highlights the importance of modeling 'national' effects to correctly estimate spatial spillovers. When we add up the coefficients of own GDP and spatial GDP effects; we get -0.145 . This implies that when state's growth is not part of national growth but part of regional growth; it will require about 6.9 percent GDP growth to reduce unemployment rate by 1 percent. We contrast this number with the own effect of -0.065 . That implies 15.4 percent state growth to reduce unemployment rate by 1 percent when the state growth not associated with either national or regional growth.

We present the estimates from the PSDM in Table 2.4. It nests both the SLX model and allows for spatial autoregression. As before, the comparison of the estimates and AICs from just state fixed effects model and the state and time effects model shows a similar pattern as in Table 2.3. The estimate of $\rho$ drops to 0.4 and indirect effects drop to - 0.1 when we include time effects. The direct effect of state GDP growth on unemployment rate change is -0.065 . AIC favors using time effects in this model. Moreover, the AIC favors this spatial Durbin model with state and time effects over all other models. This highlights the econometrically important information present in GDP 
growth spillovers beyond spatial autoregression for modeling spatial dependence in unemployment rate changes.

The economic importance of these estimates can be best highlighted by comparing the results in Table 2.2 and Table 2.4, respectively. In the state effects column of Table 2.2, consider a 1 percentage point rise in a given state's GDP growth. This rise can be a national or regional rise as well. The unemployment rate will fall by 0.23 percentage points. This translates into a 4.3 percentage point rise in GDP required to reduce unemployment by 1 percent, close to Blackley's (1991) estimates though higher than expected. When we compare this with the last column of Table 2.4, the direct effects estimates imply the state would require about 15.4 percent rise in its GDP to reduce unemployment by one percent when this rise is not associated with any national change or spatial spillovers. The direct effects coefficient is about 28 percent of the coefficient with only state fixed effects in Table 2.2.

Overall, the above results demonstrate the importance of modeling spatial spillovers to understand Okun's Law from a state perspective. The results also highlight the importance of modeling time effects for estimating the degree of spatial spillovers. Finally, the large drop in the Okun's coefficient after modeling spatial spillovers and national effects suggest that the conditions of a given state's labor market depend far less on its own GDP conditions. State growth experiences that are part of national or regional growth have a substantially bigger effect on state unemployment rates. 


\section{Estimation Results from the Sub-sample 1987 - 2009}

In this section we estimate our empirical models for the sample $1987-2009$. The results are presented in Tables 2.5 - 2.7. Each table has two columns of empirical results; one with the state fixed effects and the other with both state and time effects. The motivation for this analysis is based on Gordon's (2010) study showing that Okun's coefficient has been quite stable till 1986, but dropped after 1986. This issue of stability of Okun's Law from late 1980s has also been stressed by Knotek (2007) using national data. We are interested in two issues based on our full sample results. One, we would like to examine the quantitative drop in the direct effects after accounting for spatial spillovers and national effects. Two, we would like to examine the robustness of our model selection in the post 1986 sub-sample.

We start out by showing the results without spatial spillovers in Table 2.5 for the post 1986 period. The point estimate of Okun's coefficient is -0.2 when just state effects are used and -0.06 when time effects are also included. Both are lower than the corresponding full sample estimates thereby confirming Gordon's results. In Table 2.6, we model the spatial lag of GDP and the Okun's coefficient is about 0.04 when we include both state and time effects. In Table 2.7 using the PSDM with state and time effects, the direct effect is -0.04 . These numbers are about 34 percent lower than the corresponding number reported in Tables $2.3-2.4$. However, the direct effect is still about 21 percent of the Okun's coefficient reported in Table 2.5 with just state fixed effects. Overall, there seems to be a quantitatively important drop in the state Okun's Law coefficient.

Our second issue is the robustness of our model selection. In all the models reported from Table 2.5 to Table 2.7, AIC always selects the models with state and time 
effects suggesting national movements in the unemployment rate changes are quantitatively important. More importantly, AIC selects the PSDM over all other models even in this sub-sample thereby supporting our previous results. Finally, the estimate of $\rho$ is stable at 0.4 in the PSDMs of both samples suggesting that the degree of spatial dependence in the unemployment rates may have remained the same.

\section{Estimation Results from 10 Industrialized Countries}

A key element of our analysis using US state data is an integrated labor market with very little language, cultural or legal barriers to regional migration. Gabriel et al. (1993) stress the role of labor migration in response to different regional growth experience. Schoeb and Wildasin (2007) model the effects of labor markets integration with long-term contracts that leads to very little unemployment change in response to changes in demand. One way to examine the role of an integrated labor market in the state-level data is to compare the estimates with international data with limited labor mobility.

We use annual unemployment rate change and real GDP growth data from the same 10 industrialized countries used by Freeman (2001) for this analysis. The countries are Australia, Canada, France, Germany, Italy, Japan, Netherlands, Sweden, UK and the US. Our sample is 1978 to 2009 for comparability with the full sample results from the US states. The data was collected from the FRED II database of the St. Louis Federal Reserve Bank and the Bureau of Labor Statistics. To construct the queen spatial contiguity matrix, we assumed France and UK are neighbors since they share a maritime border. Same is true for Germany-Sweden and Netherlands-UK. 
The results from the international data are in a Tables 2.8, 2.9 and 2.10 following the same format of the previous three tables. In Table 2.8, we have the results from equation 4 without any spatial spillover effects. Okun's coefficient without time effects is -0.18 , lower than the US results, as previously reported by Kaufman (1988) and Moosa (1997). Inclusion of time effects reduces, in absolute value, this coefficient to -0.12 . This drop is not entirely unexpected since the sample does include the NAFTA years and the European Union labor market.

In Table 2.9, we report the GDP spillovers model. AIC selects the model with the time effects. That model also shows quantitatively important spatial GDP spillovers in this international sample after allowing for common time effects. In Table 2.10, we show the PSDM estimates for the international sample. As before, AIC selects the PSDM with time effects as the best model in this sample as well. The direct effect is -0.12 . This is 66 percent of the number reported in Table 2.8 without the time effects. More importantly, this is more than double the 28 percent we reported in Table 2.4 using US state-level data. The estimate of $\rho$ is -0.2 ; about half of the US number in Table 2.4. This comparison highlights the large role integrated labor market played for the state-level Okun's Law in the US.

\section{Conclusions}

In this study we estimate the state-level Okun's Law after accounting for national changes and spatial spillovers. The estimates show that state-specific growth has a small effect on state unemployment rate changes. State growth experiences that are part of national or regional growths have a substantially bigger effect on state unemployment 
rates. International data show a much larger association after accounting for time effects and spatial spillovers. The results imply that uncoordinated state-level demand management policies may not have substantial effects on unemployment rates in an integrated labor market. 
Table 2.1: National and State-level Estimates of Okun's Law

\begin{tabular}{cccc}
\hline & $\begin{array}{c}\text { National } \\
\text { Estimates }\end{array}$ & $\begin{array}{c}\text { Mean of State } \\
\text { Estimates }\end{array}$ & $\begin{array}{c}\text { Std. Deviation of } \\
\text { State Estimates }\end{array}$ \\
\hline GDP growth & $-0.445(0.039)^{*}$ & -0.263 & 0.121
\end{tabular}

Note: The dependent variable is annual change in the unemployment rates for the period 19782009. Annual growth in the quantity indexes for real GDP nationally and by state was used as the independent variable. Standard errors are reported in the parentheses. Asterisked (*) parameter estimates are statistically significant at 5 percent level of significance.

Table 2.2: Panel Estimates of Okun's Law without Spatial Effects

\begin{tabular}{lcccc}
\hline & $\begin{array}{c}\text { Common } \\
\text { Intercept }\end{array}$ & State Effects & $\begin{array}{c}\text { State and National } \\
\text { Effects }\end{array}$ & $\begin{array}{c}\text { State and Time } \\
\text { Effects }\end{array}$ \\
\hline GDP growth & $-0.214(0.007)^{*}$ & $-0.234(0.007)^{*}$ & $-0.084(0.008)^{*}$ & $-0.086(0.006)^{*}$ \\
National growth & - & - & $-0.329(0.010)^{*}$ & - \\
Log-Likelihood & -1962.14 & -1921.04 & -1554.00 & -1219.42 \\
AIC & 2.557 & 2.565 & 2.088 & 1.691 \\
\hline
\end{tabular}

Note: The dependent variable is annual change in the unemployment rates of 48 contiguous states for the period 1978-2009. Annual growth in the quantity indexes for real GDP nationally and by state was used as the independent variable. Standard errors are reported in the parentheses. Asterisked $(*)$ parameter estimates are statistically significant at 5 percent level of significance. 
Table 2.3: Panel Estimates of Okun's Law with Spatial GDP Spillovers

\begin{tabular}{|c|c|c|c|}
\hline & Common Intercept & State Effects & $\begin{array}{c}\text { State and Time } \\
\text { Effects }\end{array}$ \\
\hline GDP growth & $-0.086(0.009)^{*}$ & $-0.094(0.010)^{*}$ & $-0.065(0.007)^{*}$ \\
\hline WGDP growth & $-0.222(0.011)^{*}$ & $-0.235(0.012)^{*}$ & $-0.080(0.011)^{*}$ \\
\hline Log-Likelihood & -1793.22 & -1736.91 & -1192.04 \\
\hline AIC & 2.338 & 2.326 & 1.657 \\
\hline \multicolumn{4}{|c|}{$\begin{array}{l}\text { Note: The dependent variable is annual change in the unemployment rates of } 48 \text { contiguous } \\
\text { states for the period 1978-2009. Independent variables are state GDP growth rate and } \\
\text { spatially weighted GDP (WGDP) growth rate of the neighboring states. Annual growth in } \\
\text { the quantity indexes for real GDP by state were used to compute the GDP growth rates. } \\
\text { Standard errors are reported in the parentheses. Asterisked (*) parameter estimates are } \\
\text { statistically significant at } 5 \text { percent level of significance. }\end{array}$} \\
\hline
\end{tabular}

Table 2.4: Panel Estimates of Okun's Law from Spatial Durbin Model

\begin{tabular}{cccc}
\hline & Common Intercept & State Effects & $\begin{array}{c}\text { State and Time } \\
\text { Effects }\end{array}$ \\
\hline GDP growth & $-0.052(0.006)^{*}$ & $-0.058(0.006)^{*}$ & $-0.057(0.006)^{*}$ \\
WGDP growth & $-0.044(0.008)^{*}$ & $-0.045(0.009)^{*}$ & $-0.040(0.010)^{*}$ \\
Direct Effect & $-0.076(0.006)^{*}$ & $-0.084(0.006)^{*}$ & $-0.065(0.006)^{*}$ \\
Indirect Effect & $-0.260(0.017)^{*}$ & $-0.276(0.017)^{*}$ & $-0.099(0.015)^{*}$ \\
Total Effect & $-0.336(0.018)^{*}$ & $-0.36(0.019)^{*}$ & $-0.164(0.016)^{*}$ \\
$\rho$ & $0.714(0.018)^{*}$ & $0.716(0.017)^{*}$ & $0.414(0.028)^{*}$ \\
Log-Likelihood & -1259.79 & -1230.11 & -1098.03 \\
AIC & 1.643 & 1.665 & 1.535 \\
\hline
\end{tabular}

Note: The dependent variable is annual change in the unemployment rates of 48 contiguous states for the period 1978-2009. Independent variables are state GDP growth rate, spatially weighted GDP (WGDP) growth rate of the neighboring states and a spatial lag of the dependent variable. Annual growth in the quantity indexes for real GDP by state were used to compute the GDP growth rates. Standard errors are reported in the parentheses. Asterisked $(*)$ parameter estimates are statistically significant at 5 percent level of significance. 
Table 2.5: Panel Estimates of Okun's Law without Spatial Effects, 1987 - 2009

\begin{tabular}{ccc}
\hline & State Effects & $\begin{array}{c}\text { State and Time } \\
\text { Effects }\end{array}$ \\
\hline GDP growth & $-0.201(0.009)^{*}$ & $-0.058(0.007)^{*}$ \\
Log-Likelihood & -1339.71 & -715.03 \\
AIC & 2.516 & 1.424
\end{tabular}

Note: The dependent variable is annual change in the unemployment rates of 48 contiguous states for the period 1987-2009. Annual growth in the quantity indexes for real GDP by state was used as the independent variable. Standard errors are reported in the parentheses. Asterisked $(*)$ parameter estimates are statistically significant at 5 percent level of significance.

Table 2.6: Panel Estimates of Okun's Law with Spatial GDP Spillovers, 1987 - 2009

\begin{tabular}{ccc}
\hline & State Effects & $\begin{array}{c}\text { State and Time } \\
\text { Effects }\end{array}$ \\
\hline GDP growth & $-0.077(0.011)^{*}$ & $-0.042(0.007)^{*}$ \\
WGDP growth & $-0.24(0.014)^{*}$ & $-0.075(0.012)^{*}$ \\
Log-Likelihood & -1210.08 & -694.57 \\
AIC & 2.282 & 1.388
\end{tabular}

Note: The dependent variable is annual change in the unemployment rates of 48 contiguous states for the period 1987-2009. Independent variables are state GDP growth rate and spatially weighted GDP (WGDP) growth rate of the neighboring states. Annual growth in the quantity indexes for real GDP by state were used to compute the GDP growth rates. Standard errors are reported in the parentheses. Asterisked (*) parameter estimates are statistically significant at 5 percent level of significance. 
Table 2.7: Panel Estimates of Okun's Law from Spatial Durbin Model, 1987 - 2009

\begin{tabular}{ccc}
\hline & State Effects & $\begin{array}{c}\text { State and Time } \\
\text { Effects }\end{array}$ \\
\hline GDP growth & $-0.037(0.007)^{*}$ & $-0.035(0.006)^{*}$ \\
WGDP growth & $-0.050(0.009)^{*}$ & $-0.043(0.011)^{*}$ \\
Direct Effect & $-0.064(0.007)^{*}$ & $-0.043(0.007)^{*}$ \\
Indirect Effect & $-0.291(0.022)^{*}$ & $-0.093(0.016)^{*}$ \\
Total Effect & $-0.355(0.024)^{*}$ & $-0.136(0.017)^{*}$ \\
$\rho$ & $0.754(0.019)^{*}$ & $0.429(0.033)^{*}$ \\
Log-Likelihood & -743.60 & -617.68 \\
AIC & 1.438 & 1.249
\end{tabular}

Note: The dependent variable is annual change in the unemployment rates of 48 contiguous states for the period 1987-2009. Independent variables are state GDP growth rate, spatially weighted GDP (WGDP) growth rate of the neighboring states and a spatial lag of the dependent variable. Annual growth in the quantity indexes for real GDP by state were used to compute the GDP growth rates. Standard errors are reported in the parentheses. Asterisked $\left({ }^{*}\right)$ parameter estimates are statistically significant at 5 percent level of significance.

Table 2.8: International Panel Estimates of Okun's Law without Spatial Effects

\begin{tabular}{ccc}
\hline & Country Effects & $\begin{array}{c}\text { Country and Time } \\
\text { Effects }\end{array}$ \\
\hline GDP growth & $-0.176(0.016)^{*}$ & $-0.115(0.017)^{*}$ \\
Log-Likelihood & -364.02 & -297.00 \\
AIC & 2.343 & 2.118
\end{tabular}

Note: The dependent variable is annual change in the unemployment rates of 10 industrial countries for the period 1978-2009. Annual growth in real GDP for each country was used as the independent variable. Standard errors are reported in the parentheses. Asterisked (*) parameter estimates are statistically significant at 5 percent level of significance. 
Table 2.9: International Panel Estimates of Okun's Law with Spatial GDP Spillovers

\begin{tabular}{ccc}
\hline & Country Effects & $\begin{array}{c}\text { Country and Time } \\
\text { Effects }\end{array}$ \\
\hline GDP growth & $-0.158(0.017)^{*}$ & $-0.118(0.017)^{*}$ \\
WGDP growth & $-0.069(0.018)^{*}$ & $-0.061(0.018)^{*}$ \\
Log-Likelihood & -356.75 & -290.71 \\
AIC & 2.304 & 2.085
\end{tabular}

Note: The dependent variable is annual change in the unemployment rates of 10 industrial countries for the period 1978-2009. Independent variables are country real GDP growth rate and spatially weighted GDP (WGDP) growth rate of the neighboring countries. Annual growth in real GDP of each country was used to compute the GDP growth rates. Standard errors are reported in the parentheses. Asterisked (*) parameter estimates are statistically significant at 5 percent level of significance.

Table 2.10: International Panel Estimates of Okun's Law from Spatial Durbin Model

\begin{tabular}{ccc}
\hline & Country Effects & $\begin{array}{c}\text { Country and Time } \\
\text { Effects }\end{array}$ \\
\hline GDP growth & $-0.127(0.015)^{*}$ & $-0.110(0.015)^{*}$ \\
WGDP growth & $-0.032(0.017)^{* *}$ & $-0.045(0.017)^{*}$ \\
Direct Effect & $-0.144(0.015)^{*}$ & $-0.116(0.016)^{*}$ \\
Indirect Effect & $-0.110(0.021)^{*}$ & $-0.076(0.020)^{*}$ \\
Total Effect & $-0.254(0.029)^{*}$ & $-0.193(0.029)^{*}$ \\
$\rho$ & $0.372(0.046)^{*}$ & $0.191(0.051)^{*}$ \\
Log-Likelihood & -327.18 & -285.88 \\
AIC & 2.114 & 2.055
\end{tabular}

Note: The dependent variable is annual change in the unemployment rates of 10 industrial countries for the period 1978-2009. Independent variables are real GDP growth rate, spatially weighted GDP (WGDP) growth rate of the neighboring countries and a spatial lag of the dependent variable. Annual growth in real GDP of each country was used to compute the GDP growth rates. Standard errors are reported in the parentheses. Asterisked (*) parameter estimates are statistically significant at 5 percent level of significance. 
Figure 2.1 Examples of Comovement in the Unemployment Rates of Neighboring States
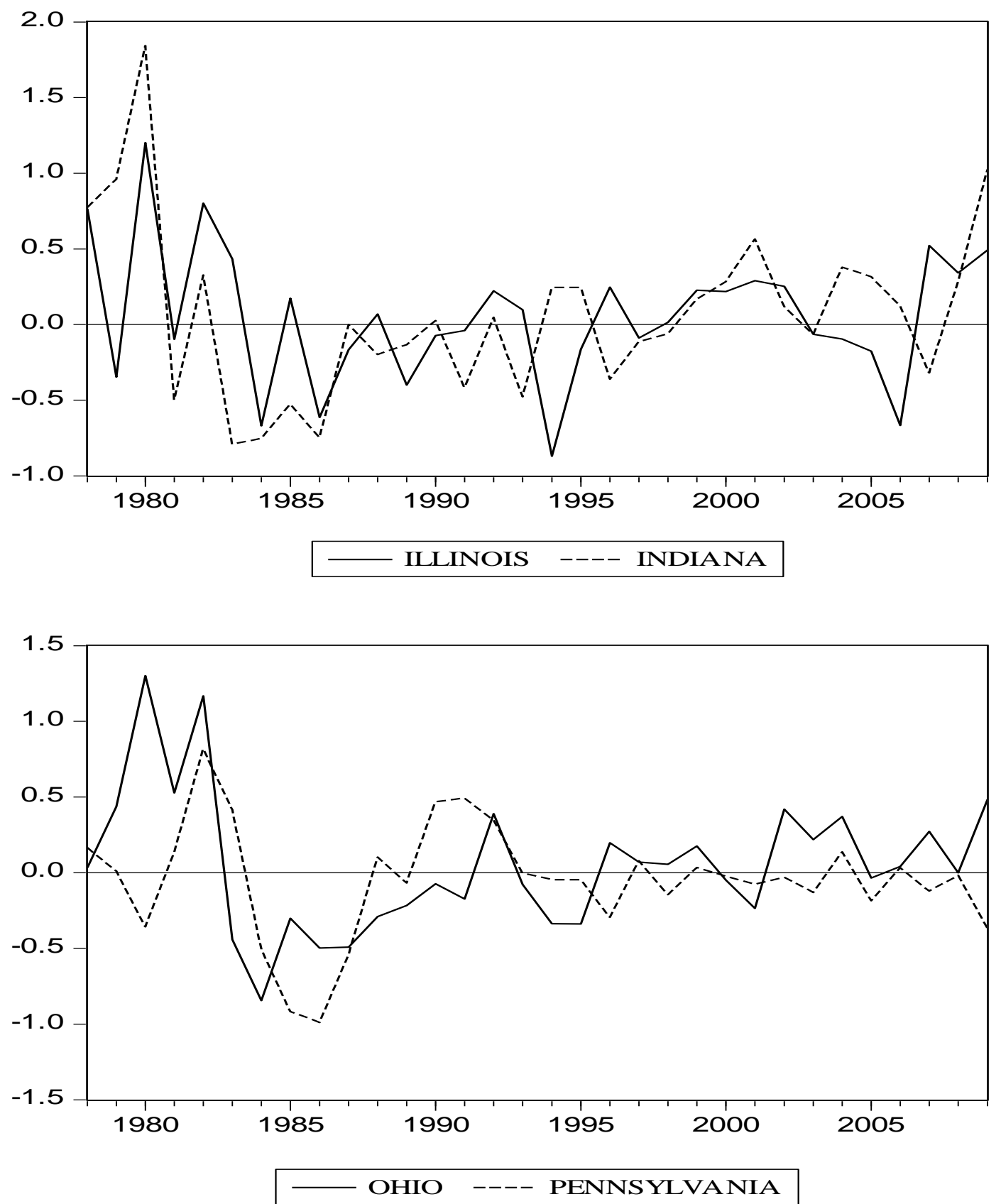

Note: The graphs show annual unemployment rate changes of the individual states after subtracting the yearly average unemployment rate changes of the 48 contiguous states. 
Figure 2.2 Moran's I coefficient for States for the Period 1978-2009

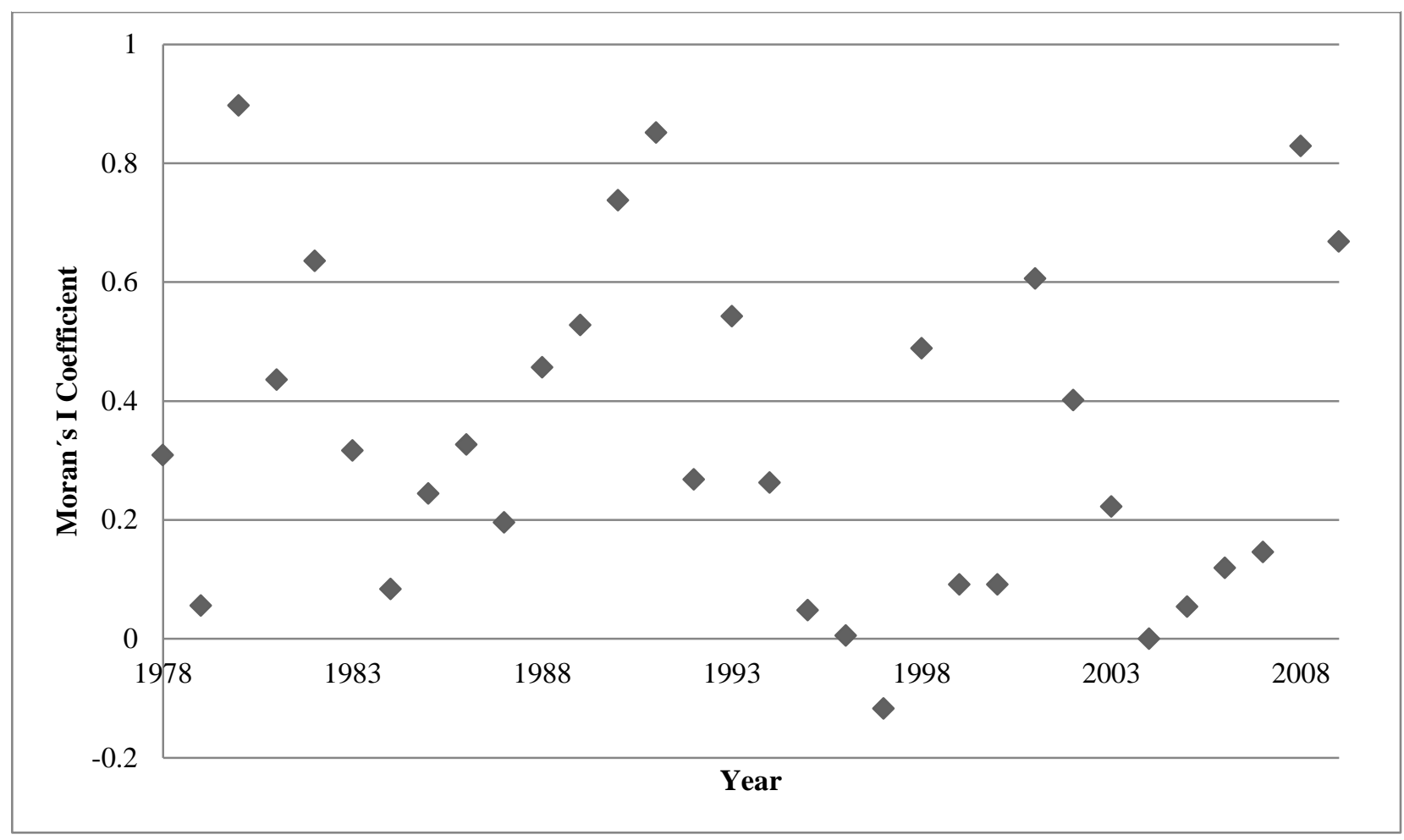

Note: The above graph shows the Moran's I coefficient obtained for each year for the period 1978-2009 


\section{Additional Estimation Results}

The following two tables, Table A.2.1 and Table A.2.2, show the estimates from panel SAR models.

Table A.2.1: Panel Estimates of Okun's Law from Spatial Autoregressive Model

\begin{tabular}{cccc}
\hline & Common Intercept & State Effects & $\begin{array}{c}\text { State and Time } \\
\text { Effects }\end{array}$ \\
\hline GDP growth & $-0.068(0.005)^{*}$ & $-0.077(0.005)^{*}$ & $-0.065(0.006)^{*}$ \\
Direct Effect & $-0.088(0.005)^{*}$ & $-0.097(0.006)^{*}$ & $-0.069(0.006)^{*}$ \\
Indirect Effect & $-0.200(0.015)^{*}$ & $-0.212(0.015)^{*}$ & $-0.051(0.006)^{*}$ \\
Total Effect & $-0.288(0.019)^{*}$ & $-0.309(0.017)^{*}$ & $-0.120(0.011)^{*}$ \\
$\rho$ & $0.764(0.014)^{*}$ & $0.749(0.019)^{*}$ & $0.458(0.026)^{*}$ \\
Log-Likelihood & -1252.43 & -1235.66 & -1100.51 \\
AIC & 1.633 & 1.673 & 1.537
\end{tabular}

Note: $\quad$ The dependent variable is annual change in the unemployment rates of 48 contiguous states for the period 1978-2009. Independent variables are state GDP growth rate and a spatial lag of the dependent variable. Annual growth in the quantity indexes for real GDP by state were used to compute the GDP growth rates. Standard errors are reported in the parentheses. Asterisked (*) parameter estimates are statistically significant at 5 percent level of significance.

Table A.2.2: Panel Estimates of Okun's Law from Spatial Autoregressive Model, 1987-2009

\begin{tabular}{ccc}
\hline & State Effects & $\begin{array}{c}\text { State and Time } \\
\text { Effects }\end{array}$ \\
\hline GDP growth & $-0.055(0.005)^{*}$ & $-0.043(0.006)^{*}$ \\
Direct Effect & $-0.072(0.007)^{*}$ & $-0.046(0.006)^{*}$ \\
Indirect Effect & $-0.203(0.022)^{*}$ & $-0.036(0.006)^{*}$ \\
Total Effect & $-0.275(0.027)^{*}$ & $-0.082(0.012)^{*}$ \\
$\rho$ & $0.802(0.015)^{*}$ & $0.472(0.031)^{*}$ \\
Log-Likelihood & -741.75 & -621.98 \\
AIC & 1.431 & 1.255
\end{tabular}

Note: The dependent variable is annual change in the unemployment rates of 48 contiguous states for the period 1987-2009. Independent variables are state GDP growth rate and a spatial lag of the dependent variable. Annual growth in the quantity indexes for real GDP by state were used to compute the GDP growth rates. Standard errors are reported in the parentheses. Asterisked $(*)$ parameter estimates are statistically significant at 5 percent level of significance. 
The following table, Table A.2.3, show the estimates using the gap version of Okun's Law. We use the Hodrick-Prescott filter to measure the output and unemployment gaps for the 48 contiguous states. The first two columns do not allow for spatial feedbacks. The last column reports the PSDM estimates.

Table A.2. 3: Panel Estimates of Okun's Law from Spatial Durbin Model Using Gaps

\begin{tabular}{cccc}
\hline & State Effects & $\begin{array}{c}\text { State and Time } \\
\text { Effects }\end{array}$ & $\begin{array}{c}\text { State and Time } \\
\text { Effects }\end{array}$ \\
\hline GDP gap & $-0.229(0.008)^{*}$ & $-0.071(0.007)^{*}$ & $-0.049(0.007)^{*}$ \\
WGDP gap & - & - & $-0.044(0.011)^{*}$ \\
Direct Effect & - & - & $-0.056(0.006)^{*}$ \\
Indirect Effect & - & - & $-0.089(0.015)^{*}$ \\
Total Effect & - & - & $-0.145(0.017)^{*}$ \\
P & - & - & $0.352(0.030)^{*}$ \\
Log-Likelihood & -1733.33 & -1027.23 & -942.36 \\
AIC & 2.320 & 1.442 & 1.332 \\
\hline
\end{tabular}

Note: $\quad$ The dependent variable is the Hodrick-Prescott filtered unemployment rate gap of 48 contiguous states for the period 1978-2009. Independent variables are Hodrick-Prescott filtered state GDP gap, spatially weighted GDP (WGDP) gap of the neighboring states and a spatial lag of the dependent variable. Annual quantity indexes for real GDP by state were used to compute the GDP gaps. Standard errors are reported in the parentheses. Asterisked $\left(^{*}\right)$ parameter estimates are statistically significant at 5 percent level of significance. 


\section{Chapter 3}

\section{Okun's Law and Urban Spillovers}

\section{Introduction}

Arthurs Okun's (1962) influential paper opened the debate on the empirical link between unemployment and output. Ever since, a large number of empirical and theoretical papers on the so called Okun`s Law have been written; although most of these papers have focused on a national rather than a regional level. Knotek (2007) and Gordon (2010) for example use time series technique to analyze the stability of this relationship for the United States. Kaufman (1988) compares the Okun's coefficient among industrialized countries concluding that differences in responses of unemployment to changes in GDP are due to labor productivity and labor force participation rate. Moosa (1997) also uses time series to provide evidence on the variation in the Okun's coefficient among countries, and these are mostly due to rigidities in labor markets and other institutional differences. Both authors conclude that unemployment responses to output are larger in the US than in other countries.

At a regional level Blackley (1991) finds the Okun's coefficient for the 26 largest states in the United States for the years 1970-1986. He obtained the "standard" result that on average real GDP must grow at a rate of 3.1 percent in order to decrease the 
unemployment rate by one percent. The author concluded that inter-state differences in the distribution of age and gender of the labor force, different tax policies and industries leads to differences in Okun's coefficient among states. Freeman (2000) on the other hand found little differences in the regional estimates for the U.S. Adanu (2005) made a comparison of Okun's coefficient for the 10 provinces of Canada. The author concluded that the more industrialized a province is, the more responsive unemployment is to changes in real GDP.

Yazgan and Yilmazkuday (2008) used spatial econometric techniques to show evidence for the spatial convergence of the Okun's coefficient over time within the United States. Using annual data for 48 mainland states for the period $1978-2002$ the authors found the existence of geographical "Okun's Clusters".

In the previous chapter we analyzed the behavior of state-level Okun's Law and the spatial dependence in the state unemployment data. Molho (1995) suggests two economic reasons behind the observed spatial dependence: labor migration and commuting. Blanchard and Katz (1992) suggest labor migration as the predominant mechanism to reach equilibrium between state unemployment rates following economic shocks. This study focuses on unemployment rates in metropolitan statistical areas (MSA) in the US. This should lead to two important changes. One, most of the commuting happens within the MSAs. However, an MSA could be spread across several state lines that can form a source of spatial dependence in state data. Two, MSAs are smaller geographical units than states which should lead to relatively higher labor mobility between them than between the states. Both should change the degree of spatial dependence in the unemployment data. Moreover, the Okun's Law coefficient should be lower due to higher labor mobility. 
In this paper we estimate Okun's Law at an urban level accounting for national time effects and spatial spillovers in a panel dataset. The estimates show that MSAspecific growth has a small effect on the MSA's unemployment rate. Additionally, we use different specifications for the weight matrix to check the robustness of our results. Theoretically we would expect no change, as showed in Lesage and Pace (2010) who found little evidence that different specification for the weight matrix leaves to differences in estimates if we observe the true partial derivatives. Our findings support the existence of an integrated labor market at a national level rather than the predominance of urban-regional labor markets.

We also compare our results for the same period using state-level data. This allows us to analyze empirically the Modifiable Areal Unit Problem (MAUP) that deals with the arbitrariness and irregularity of spatial areal data. It is well known in the spatial econometric literature that the estimation results vary with the aggregation and resolution level of the data. Studies like Haggett (1965) and Arbia (1988) show that conclusions derived at one level of aggregation and resolution may not hold for another level. Our results are consistent with these studies. The effect of state-specific growth on unemployment seems to be larger than that of the MSA; at the same time the spatial dependence at state level is lower than at MSA.

In the following section we do some preliminary data analysis, lay out the formal spatial models and describe the data and estimation techniques. In Section III we discuss the estimation results. In section IV we compare our results with state level data. We conclude in section $\mathrm{V}$. 


\section{Data and Model Specifications}

\section{a. Preliminary data analysis}

The basic differenced version of Okun's law that we use is the following equation:

1. $\Delta U_{t}=\beta_{1}+\beta_{2} \Delta g d p_{t}+\varepsilon_{t}$

Where $\Delta U$ is the change in unemployment rate, $\Delta g d p$ is the change in the natural log of real GDP, $t$ is a time index where $t=1 \ldots T$, and $\varepsilon$ represents the error term $\left(\varepsilon \sim \mathrm{N}\left(0, \sigma^{2}\right)\right)$. The Okun's coefficient is calculated as $\frac{-1}{\beta_{2}}$; we use a minus sign because we expect $\beta_{2}$ to be negative.

When we extend this to a panel data set, the basic model is adjusted to account for MSA-specific fixed effects as follows:

2. $\Delta U_{i, t}=\beta_{1}+\beta_{i}+\beta_{2} \Delta g d p_{i, t}+\varepsilon_{i, t}$

The results for this model are in the first two columns of Table 3.1. The first column does not consider MSA-specific fixed effects. Both estimates are close to -0.2. Based on these estimates, we will augment our panel data model to explicitly consider the national changes. We have two alternatives. The first alternative is to introduce national growth explicitly in the model. The basic panel model from equation 2 is adjusted to allow for national growth as follows:

3. $\Delta U_{i, t}=\beta_{1}+\beta_{i}+\beta_{n} \Delta g d p_{t}^{n}+\beta_{2} \Delta g d p_{i, t}+\varepsilon_{i, t}$

where $\Delta g d p^{n}$ is the national real GDP growth rate. The second alternative is to allow for time effects as follows:

4. $\Delta U_{i, t}=\beta_{1}+\beta_{i}+\beta_{t}+\beta_{2} \Delta g d p_{i, t}+\varepsilon_{i, t}$ 
where $\beta_{i}$ accounts for MSA-specific fixed effects and $\beta_{t}$ accounts for time effects.

In the third column of Table 3.1, we show the estimates of equation 3 . The sum of the coefficients of GDP growth and national growth adds up to -0.61 . In the fourth column of Table 3.1, we show the estimates of equation 4 that accounts for national movements in the unemployment rate changes beyond national output growth. The coefficient of MSA GDP growth is very similar to the one reported in the previous column.

Our third consideration is allowing for spatial spillovers between MSA's. In the next section we developed formal spatial econometric models that allow us to capture these spillovers; however, as an initial approach to observe if the data has a spatial dependence pattern we obtain the Moran's I coefficient for each year. The Moran's I coefficient is a measure of spatial autocorrelation that also allows us test the null hypothesis of spatial independence. Some authors have pointed out that it is not a proper statistical test because it does not consider an explicit alternative hypothesis (Arbia 2006); however, we use the Moran's I coefficients only in this exploratory phase to obtain a panoramic view on how the data behaves. Figure 3.1 shows the Moran's I coefficients for each year (2002-2009) using two different spatial weight matrices -we will return over the weight matrices later- and in both cases the Moran's I coefficients are positive and above 0.3. These results suggest that there could be important spatial dependence in our data.

\section{b. Spatial model specification}

We extend equation 4 to allow for spatial dependence by specifying the Panel Spatial Durbin Model (hereafter PSDM): 
5. $\Delta U_{i, t}=\beta_{1}+\beta_{i}+\beta_{t}+\beta_{2} \Delta g d p_{i, t}+\theta \sum_{j=1}^{N} w_{i, j} \Delta g d p_{j, t}+\rho \sum_{j=1}^{N} w_{i, j} \Delta U_{j, t}+\varepsilon_{i, t}$

Where $i=1 \ldots N, \varepsilon$ represents the idiosyncratic term $\left(\varepsilon \sim \operatorname{MVN}\left(0, \sigma^{2} I_{n}\right)\right), \rho$ measures the spatial dependence in the dependent variable. Finally, $\sum_{j=1}^{N} w_{i, j} \Delta g d p_{j, t}$ and $\sum_{j=1}^{N} w_{i, j} \Delta U_{j, t}$ are the spatial feedbacks of real GDP growth and change in unemployment rate. They are the weighted average of the values of real GDP growth and change in unemployment rate for the "neighbors" of MSA i. To model the spatial spillovers, we use two different weight matrices; this allows us to check the robustness of our results. Before explaining each of our weight matrices, it is worth mentioning that the two matrices have zero on the main diagonal ${ }^{8}$ and the entire matrix is normalized in such a way that the individual rows sum up to one.

For the first weight matrix, we define any element $w_{i, j} \forall i \neq j$ as one if and only if MSA $i$ is a neighbor of MSA $j$, and zero otherwise; however MSA's do not have a common border, for this reason we define neighboring MSA's as any two MSA's that are inside a range. For our particular case the range is roughly 200 miles; this range is the minimum that ensures that any MSA has at least one neighbor. The second matrix is the inverse distance squared. For any element $w_{i, j}=\frac{1}{d^{2}{ }_{i, j}} \forall i \neq j$ where $\mathrm{d}$ is the distance in miles between MSA $i$ and MSA $j$. The idea is that the impact decreases more sharply over distance ${ }^{9}$.

\footnotetext{
${ }^{7}$ We define the meaning of neighboring MSA's later on in this chapter.

${ }^{8}$ MSA i cannot be a neighbor of MSA $i$.

${ }^{9}$ More sharply compared to the inverse distance matrix. We also calculated our results using the inverse distance weight matrix and the results are quite similar to those presented here.
} 
In the PSDM specified in equation 5, we allow for a spatial lag of GDP growth and a spatial lag of the dependent variable. Two special cases are worth mentioning. If the coefficient $\rho$ is restricted to zero, we have a panel SLX model. If $\theta$ is restricted to zero, we have a panel spatial autoregessive model (SAR). If we restrict both coefficients to zero, we get back the simple panel model described in equation 4. We use the AIC to compare empirical performance of the different model specifications.

Econometrically, omission of spatial variables in spatially dependent data leads to biased least squares estimates. Finally, as LeSage and Pace (2009) shows, unobserved common properties between spatial neighbors that are associated with other explanatory variables can be modeled as a spatial Durbin model.

Before estimating the PSDM, we feel it is necessary to discuss the interpretation of our empirical output; especially the direct effect and the indirect effect in the context of spatial autoregressive and spatial Durbin models. Recently, LeSage and Dominguez (2010) lucidly explained this issue in the context of the public choice literature. They stress that the coefficient of an explanatory variable from least squares and the coefficient of the same variable from spatial models with an autoregressive lag should not be compared. Instead, one should use the "direct" effect of that variable in spatially dependent models.

The type of panel data we are analyzing adds another issue to be considered. A lot of the variation in the dependent variable is common to all the MSA's in the sample. We term it as the 'national' effects. Ignoring this feature will bias the estimates of actual spatial spillover present in the data. We capture this by using the time effects in the panel data. 


\section{c. Data description}

The annual data for 358 Metropolitan Statistical Areas of the United States over the period 2002-2009 was obtained from Bureau of Economic Analysis and Bureau of Labor Statistics. We do not consider MSA's from Alaska, Hawaii or Puerto Rico. We use maximum likelihood procedures to estimate the PSDM since the least squares estimates will be biased ${ }^{10}$.

\section{Estimation Results}

Tables 3.2 and 3.4 show the results for the SLX model for the two different matrix specifications. We notice that all the coefficients are negative and non-zero at a five percent level. Furthermore the coefficient for the spatially weighted GDP variable is as much as six times that of own GDP for the case of a common intercept (column 1) and when we control for MSA fixed effects (column 2). This suggests the importance of modeling spatial spillovers. This relationship becomes almost one to one after accounting for fixed time effects, showing the importance of accounting for national effects.

Tables 3.3 and 3.5 present the estimates from the PSDM for the two different matrix specifications. As before the indirect effect accounts for as much as six times that of the direct effect either for a common intercept or controlling for MSA fixed effects. This relationship does not change when we include time effects for the case of the inverse distance squared weight matrix but becomes a "two to one" relationship when we look at neighboring MSA's within 200 miles. Once more these results stress the importance of modeling spatial spillovers and national effects.

\footnotetext{
${ }^{10}$ The MATLAB codes to solve panel SAR models and PSDM by Paul Elhorst can be found at http://www.regroningen.nl/index_en.html
} 


\section{Estimation Results from State level data}

We now turn our attention to states, which is also a labor market with almost nonexisting frictions to labor migration. Like the MSA's, we have a market with only small cultural differences, a common language and almost completely free labor mobility. There is, however, one crucial difference between these two aggregation levels. While each state has its own fiscal policy, MSA's do not. Put another way, each state has its own fiscal tools that could be used to attract investment and increase employment. Furthermore MSA's that cross state's borders are subject to more than one fiscal policy.

The annual data for 48 contiguous states of the United States over the period 2002-2009 was obtained from the Bureau of Economic Analysis and Bureau of Labor Statistics. We used the growth in quantity indexes to compute real GDP growth. In order to calculate our results, we also constructed a queen first order spatial contiguity matrix and an inverse distance squared matrix. The elements of the former matrix are composed only of ones or zeros, depending on whether or not states have a common border, while the later has been explained already in the MSA's chapter. Both matrices have been row normalized such that each row sums up to one.

The results are shown in tables 3.6 through 3.10. Our results are compared with those obtained for the MSA based on their weight matrix similarities. Comparing table six with its counterpart for MSA's, we observe that the state's GDP coefficient is larger than that of the MSA's, even when we include state and/or time effects. If we compare tables two and seven or tables four and nine we notice the same, that is, the coefficient for state's GDP is larger than the coefficient for MSA's GDP. 
Comparing tables three and eight or similarly tables five and ten we observe that the direct effect is larger for states than for MSA's showing a similar pattern as the previously mentioned. We can also observe that in all cases the coefficient for GDP spillovers is at least twice that of state's GDP.

We observe an increase in spatial dependence given by a higher value of rho when moving from state level to MSA's level. According to the empirical literature, as spatial units become large, spatial dependence falls as shown in Anselin and Rey (2010). In our particular case the two source of spatial dependence in unemployment are due to labor migration and commuting. Assuming that labor migration is the driving force behind spatial dependence on unemployment, our results indicate that inter-urban migration is higher than inter-state migration, thus the higher value of rho using MSA data.

These results suggest that even though state-specific growth seems to have a larger impact than MSA-specific growth on their own respective unemployment rate, both are still heavily dependent on national and regional growth experiences.

\section{Conclusions}

In this paper we estimated Okun's Law from an urban perspective using Metropolitan Statistical Areas. Results show that MSA unemployment rates are heavily dependent on other regional growth experiences and national conditions. One possible reason for this pattern could be industry clusters; for example MSA's in the oil states (Texas Louisiana and Oklahoma) may be affected by the same specific shocks.

The other possible explanation for this pattern is similar to that outlined by Blanchard and Katz (1992) that regional labor markets adjust quickly, attracting workers 
thus affecting the labor market. This would imply the existence of a powerful national labor market with regional labor markets being far less important. 
Table 3.1: Panel Estimates of Okun's Law without Spatial Effects

\begin{tabular}{lcccc}
\hline & $\begin{array}{c}\text { Common } \\
\text { Intercept }\end{array}$ & MSA Effects & $\begin{array}{c}\text { MSA and National } \\
\text { Effects }\end{array}$ & $\begin{array}{c}\text { MSA and Time } \\
\text { Effects }\end{array}$ \\
\hline GDP growth & $-0.169(0.005)^{*}$ & $-0.188(0.006)^{*}$ & $-0.046(0.004)^{*}$ & $-0.056(0.004)^{*}$ \\
National growth & - & & & \\
Log-Likelihood & -4574.62 & -4487.33 & $-0.572(0.008)^{*}$ & - \\
AIC & 3.195 & 3.384 & 2.305 & -2515.48 \\
\hline
\end{tabular}

Note: The dependent variable is annual change in the unemployment rates of 358 MSA's for the period 2002-2009. Annual growth in the real GDP nationally and by MSA was used as the independent variable. Standard errors are reported in the parentheses. Asterisked (*) parameter estimates are statistically significant at 5 percent level of significance.

Table 3.2: Panel Estimates of Okun's Law with Spatial GDP Spillovers.

\begin{tabular}{lccc}
\hline & Common Intercept & MSA Effects & $\begin{array}{c}\text { MSA and Time } \\
\text { Effects }\end{array}$ \\
\hline GDP growth & $-0.059(0.005)^{*}$ & $-0.062(0.006)^{*}$ & $-0.045(0.004)^{*}$ \\
WGDP growth & $-0.319(0.009)^{*}$ & $-0.354(0.009)^{*}$ & $-0.083(0.008)^{*}$ \\
Log-Likelihood & -4040.31 & -3866.53 & -2461.98 \\
AIC & 2.823 & 2.951 & 1.975 \\
\hline Note: & $\begin{array}{l}\text { The dependent variable is annual change in the unemployment rates of 358 MSA's for } \\
\text { the period 2002-2009. Independent variables are MSA's real GDP growth rate and } \\
\text { spatially weighted GDP (WGDP) growth rate. Standard errors are reported in the } \\
\text { parentheses. Asterisked (*) parameter estimates are statistically significant at 5 percent } \\
\text { level of significance. MSA's within 200 miles are considered neighbors. }\end{array}$
\end{tabular}


Table 3.3: Panel Estimates of Okun's Law from Spatial Durbin Model.

\begin{tabular}{cccc}
\hline & Common Intercept & MSA Effects & $\begin{array}{c}\text { MSA and Time } \\
\text { Effects }\end{array}$ \\
\hline GDP growth & $-0.038(0.003)^{*}$ & $-0.039(0.003)^{*}$ & $-0.039(0.003)^{*}$ \\
WGDP growth & $-0.003(0.005)$ & $-0.006(0.005)$ & $0.002(0.007)$ \\
Direct Effect & $-0.049(0.003)^{*}$ & $-0.050(0.003)^{*}$ & $-0.042(0.003)^{*}$ \\
Indirect Effect & $-0.340(0.035)^{*}$ & $-0.368(0.036)^{*}$ & $-0.098(0.023)^{*}$ \\
Total Effect & $-0.389(0.036)^{*}$ & $-0.418(0.037)^{*}$ & $-0.140(0.025)^{*}$ \\
P & $0.892(0.009)^{*}$ & $0.892(0.009)^{*}$ & $0.740(0.018)^{*}$ \\
Log-Likelihood & -2236.91 & -2081.12 & -2001.22 \\
AIC & 1.565 & 1.705 & 1.654
\end{tabular}

Note: The dependent variable is annual change in the unemployment rates of $358 \mathrm{MSA}$ 's for the period 2002-2009. Independent variables are MSA's real GDP growth rate and spatially weighted GDP (WGDP) growth rate. Standard errors are reported in the parentheses. Asterisked $(*)$ parameter estimates are statistically significant at 5 percent level of significance. MSA's within 200 miles are considered neighbors.

Table 3.4: Panel Estimates of Okun's Law with Spatial GDP Spillovers.

\begin{tabular}{lccc}
\hline & Common Intercept & MSA Effects & $\begin{array}{c}\text { MSA and Time } \\
\text { Effects }\end{array}$ \\
\hline GDP growth & $-0.056(0.006)^{*}$ & $-0.056(0.006)^{*}$ & $-0.046(0.004)^{*}$ \\
WGDP growth & $-0.323(0.009)^{*}$ & $-0.359(0.009)^{*}$ & $-0.065(0.009)^{*}$ \\
Log-Likelihood & -4058.29 & -3891.26 & -2485.79 \\
AIC & 2.836 & 2.968 & 1.992 \\
\hline Note: & $\begin{array}{l}\text { The dependent variable is annual change in the unemployment rates of 358 MSA's for } \\
\text { the period 2002-2009. Independent variables are MSA's real GDP growth rate and } \\
\text { spatially weighted GDP (WGDP) growth rate. Standard errors are reported in the } \\
\text { parentheses. Asterisked (*) parameter estimates are statistically significant at 5 percent } \\
\text { level of significance. Weight matrix based on inverse distance squared. }\end{array}$
\end{tabular}


Table 3.5: Panel Estimates of Okun's Law from Spatial Durbin Model.

\begin{tabular}{cccc}
\hline & Common Intercept & MSA Effects & $\begin{array}{c}\text { MSA and Time } \\
\text { Effects }\end{array}$ \\
\hline GDP growth & $-0.038(0.003)^{*}$ & $-0.039(0.003)^{*}$ & $-0.039(0.003)^{*}$ \\
WGDP growth & $0.011(0.005)^{*}$ & $0.011(0.005)^{*}$ & $0.004(0.007)$ \\
Direct Effect & $-0.043(0.003)^{*}$ & $-0.044(0.003)^{*}$ & $-0.044(0.003)^{*}$ \\
Indirect Effect & $-0.390(0.062)^{*}$ & $-0.391(0.063)^{*}$ & $-0.315(0.076)^{*}$ \\
Total Effect & $-0.433(0.062)^{*}$ & $-0.435(0.064)^{*}$ & $-0.359(0.077)^{*}$ \\
P & $0.937(0.010)^{*}$ & $0.936(0.010)^{*}$ & $0.899(0.015)^{*}$ \\
Log-Likelihood & -2125.65 & -1961.33 & -1959.95 \\
AIC & 1.487 & 1.622 & 1.625
\end{tabular}

Note: The dependent variable is annual change in the unemployment rates of 358 MSA's for the period 2002-2009. Independent variables are MSA's real GDP growth rate and spatially weighted GDP (WGDP) growth rate. Standard errors are reported in the parentheses. Asterisked $(*)$ parameter estimates are statistically significant at 5 percent level of significance. Weight matrix based on inverse distance squared.

Table 3.6: Panel Estimates of Okun's Law without Spatial Effects.

\begin{tabular}{lcccc}
\hline & $\begin{array}{c}\text { Common } \\
\text { Intercept }\end{array}$ & State Effects & $\begin{array}{c}\text { State and National } \\
\text { Effects }\end{array}$ & $\begin{array}{c}\text { State and Time } \\
\text { Effects }\end{array}$ \\
\hline GDP growth & $-0.309(0.020)^{*}$ & $-0.343(0.023)^{*}$ & $-0.095(0.017)^{*}$ & $-0.088(0.014)^{*}$ \\
National growth & & & $-0.518(0.021)^{*}$ & \\
Log-Likelihood & -535.83 & -521.59 & -325.01 & -243.43 \\
AIC & 2.801 & 2.972 & 1.953 & 1.559 \\
\hline
\end{tabular}

Note: The dependent variable is annual change in the unemployment rates of 48 contiguous states for the period 2002-2009. Annual growth in the real GDP nationally and by state was used as the independent variable. Standard errors are reported in the parentheses. Asterisked $(*)$ parameter estimates are statistically significant at 5 percent level of significance. 
Table 3.7: Panel Estimates of Okun's Law with Spatial GDP Spillovers.

\begin{tabular}{cccc}
\hline & Common Intercept & State Effects & $\begin{array}{c}\text { State and Time } \\
\text { Effects }\end{array}$ \\
\hline GDP growth & $-0.122(0.020)^{*}$ & $-0.127(0.020)^{*}$ & $-0.068(0.013)^{*}$ \\
WGDP growth & $-0.409(0.026)^{*}$ & $-0.478(0.027)^{*}$ & $-0.165(0.024)^{*}$ \\
Log-Likelihood & -442.10 & -394.29 & -218.35 \\
AIC & 2.318 & 2.314 & 1.434 \\
\hline
\end{tabular}

Note: The dependent variable is annual change in the unemployment rates of 48 contiguous states for the period 2002-2009. Independent variables are state's real GDP growth rate and spatially weighted GDP (WGDP) growth rate. Standard errors are reported in the parentheses. Asterisked $(*)$ parameter estimates are statistically significant at 5 percent level of significance. Weight matrix based on first order contiguity.

Table 3.8: Panel Estimates of Okun's Law from Spatial Durbin Model.

\begin{tabular}{cccc}
\hline & Common Intercept & State Effects & $\begin{array}{c}\text { State and Time } \\
\text { Effects }\end{array}$ \\
\hline GDP growth & $-0.056(0.012)^{*}$ & $-0.055(0.012)^{*}$ & $-0.057(0.012)^{*}$ \\
WGDP growth & $-0.092(0.019)^{*}$ & $-0.123(0.021)^{*}$ & $-0.119(0.023)^{*}$ \\
Direct Effect & $-0.104(0.012)^{*}$ & $-0.106(0.013)^{*}$ & $-0.069(0.012)^{*}$ \\
Indirect Effect & $-0.499(0.051)^{*}$ & $-0.556(0.044)^{*}$ & $-0.189(0.029)^{*}$ \\
Total Effect & $-0.603(0.055)^{*}$ & $-0.663(0.049)^{*}$ & $-0.257(0.033)^{*}$ \\
P & $0.752(0.030)^{*}$ & $0.731(0.031)^{*}$ & $0.306(0.061)^{*}$ \\
Log-Likelihood & -273.62 & -251.09 & -208.32 \\
AIC & 1.446 & 1.573 & 1.387
\end{tabular}

Note: The dependent variable is annual change in the unemployment rates of 48 states for the period 2002-2009. Independent variables are state's real GDP growth rate and spatially weighted GDP (WGDP) growth rate. Standard errors are reported in the parentheses. Asterisked (*) parameter estimates are statistically significant at 5 percent level of significance. Weight matrix based on first order contiguity. 
Table 3.9: Panel Estimates of Okun's Law with Spatial GDP Spillovers.

\begin{tabular}{lccc}
\hline & Common Intercept & State Effects & $\begin{array}{c}\text { State and Time } \\
\text { Effects }\end{array}$ \\
\hline GDP growth & $-0.092(0.018)^{*}$ & $-0.102(0.019)^{*}$ & $-0.078(0.013)^{*}$ \\
WGDP growth & $-0.566(0.029)^{*}$ & $-0.619(0.029)^{*}$ & $-0.204(0.043)^{*}$ \\
Log-Likelihood & -404.77 & -356.90 & -230.76 \\
AIC & 2.124 & 2.119 & 1.499 \\
\hline Note: & $\begin{array}{l}\text { The dependent variable is annual change in the unemployment rates of } 48 \text { contiguous } \\
\text { states for the period 2002-2009. Independent variables are state's real GDP growth rate } \\
\text { and spatially weighted GDP (WGDP) growth rate. Standard errors are reported in the } \\
\text { parentheses. Asterisked (*) parameter estimates are statistically significant at 5 percent } \\
\text { level of significance. Weight matrix based on inverse distance squared. }\end{array}$
\end{tabular}

Table 3.10: Panel Estimates of Okun's Law from Spatial Durbin Model.

\begin{tabular}{cccc}
\hline & Common Intercept & State Effects & $\begin{array}{c}\text { State and Time } \\
\text { Effects }\end{array}$ \\
\hline GDP growth & $-0.066(0.012)^{*}$ & $-0.066(0.012)^{*}$ & $-0.072(0.012)^{*}$ \\
WGDP growth & $-0.086(0.028)^{*}$ & $-0.125(0.031)^{*}$ & $-0.157(0.040)^{*}$ \\
Direct Effect & $-0.092(0.012)^{*}$ & $-0.095(0.031)^{*}$ & $-0.081(0.031)^{*}$ \\
Indirect Effect & $-0.677(0.087)^{*}$ & $-0.709(0.013)^{*}$ & $-0.290(0.012)^{*}$ \\
Total Effect & $-0.768(0.089)^{*}$ & $-0.804(0.031)^{*}$ & $-0.371(0.073)^{*}$ \\
P & $0.802(0.033)^{*}$ & $0.759(0.069)^{*}$ & $0.378(0.086)^{*}$ \\
Log-Likelihood & -266.55 & -240.38 & -223.86 \\
AIC & 1.409 & 1.516 & 1.468
\end{tabular}

Note: The dependent variable is annual change in the unemployment rates of 48 states for the period 2002-2009. Independent variables are state's real GDP growth rate and spatially weighted GDP (WGDP) growth rate. Standard errors are reported in the parentheses. Asterisked (*) parameter estimates are statistically significant at 5 percent level of significance. Weight matrix based on inverse distance squared. 


\section{Additional Estimation Results}

The following three tables, Table A.3.1 and A.3.2, show the estimates from panel SAR models.

Table A.3.1: Panel Estimates of Okun's Law from Spatial Autoregressive Model. MSA's within 200 miles are considered neighbors.

\begin{tabular}{cccc}
\hline & Common Intercept & MSA Effects & $\begin{array}{c}\text { MSA and Time } \\
\text { Effects }\end{array}$ \\
\hline GDP growth & $-0.039(0.002)^{*}$ & $-0.039(0.002)^{*}$ & $-0.039(0.003)^{*}$ \\
Direct Effect & $-0.049(0.003)^{*}$ & $-0.051(0.003)^{*}$ & $-0.042(0.003)^{*}$ \\
Indirect Effect & $-0.328(0.028)^{*}$ & $-0.356(0.029)^{*}$ & $-0.103(0.011)^{*}$ \\
Total Effect & $-0.377(0.029)^{*}$ & $-0.407(0.032)^{*}$ & $-0.146(0.013)^{*}$ \\
P & $0.897(0.007)^{*}$ & $0.902(0.007)^{*}$ & $0.733(0.018)^{*}$ \\
Log-Likelihood & -2236.98 & -2081.46 & -2001.25 \\
AIC & 1.564 & 1.705 & 1.653
\end{tabular}

Note: The dependent variable is annual change in the unemployment rates of 358 MSA's for the period 2002-2009. Independent variables are MSA's real GDP growth rate and spatially weighted GDP (WGDP) growth rate. Standard errors are reported in the parentheses. Asterisked (*) parameter estimates are statistically significant at 5 percent level of significance. 
Table A.3.2: Panel Estimates of Okun's Law from Spatial Autoregressive Model. Weight matrix based on inverse distance squared.

\begin{tabular}{cccc}
\hline & Common Intercept & MSA Effects & $\begin{array}{c}\text { MSA and Time } \\
\text { Effects }\end{array}$ \\
\hline GDP growth & $-0.036(0.003)^{*}$ & $-0.037(0.003)^{*}$ & $-0.039(0.003)^{*}$ \\
Direct Effect & $-0.042(0.003)^{*}$ & $-0.043(0.003)^{*}$ & $-0.044(0.003)^{*}$ \\
Indirect Effect & $-0.445(0.051)^{*}$ & $-0.441(0.049)^{*}$ & $-0.310(0.056)^{*}$ \\
Total Effect & $-0.487(0.052)^{*}$ & $-0.484(0.049)^{*}$ & $-0.354(0.058)^{*}$ \\
P & $0.925(0.008)^{*}$ & $0.922(0.008)^{*}$ & $0.888(0.016)^{*}$ \\
Log-Likelihood & -2127.72 & -1962.91 & -1960.01 \\
AIC & 1.488 & 1.622 & 1.625
\end{tabular}

Note: The dependent variable is annual change in the unemployment rates of 358 MSA's for the period 2002-2009. Independent variables are MSA's real GDP growth rate and spatially weighted GDP (WGDP) growth rate. Standard errors are reported in the parentheses. Asterisked (*) parameter estimates are statistically significant at 5 percent level of significance. 
Figure 3.1: Moran's I for MSA's for the Period 2002-2009
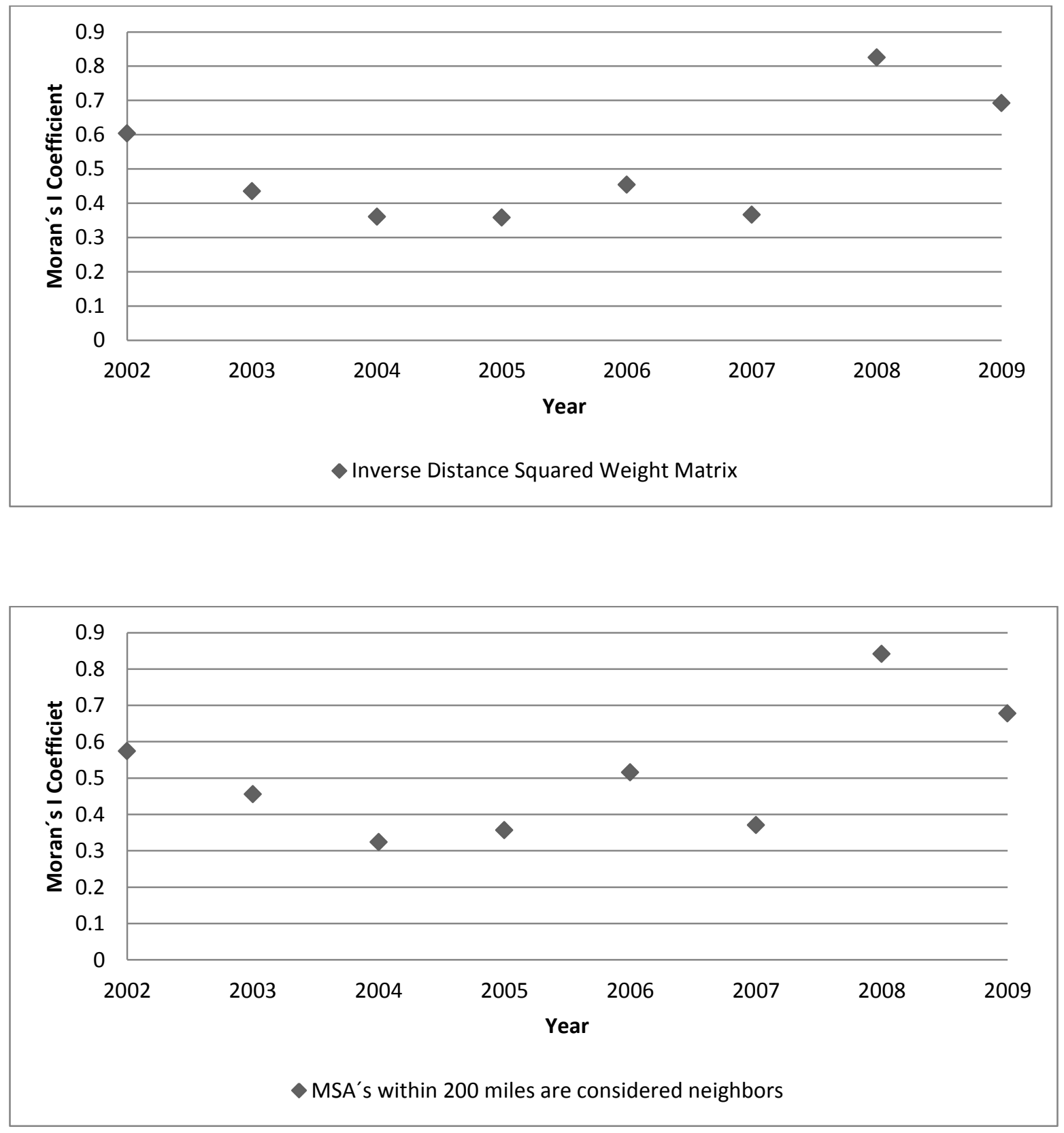

Note: The above graphs show the Moran's I coefficient obtained for each year for the period 2002-2009. 


\section{Chapter 4}

\section{Forecasting U.S. State Unemployment: Role of Spatial}

\section{Spillovers}

\section{Introduction}

Forecasting unemployment has been widely documented by economists and econometricians for a long time. In the attempt to find a good model, researches have tried different econometric methodologies as well as a broad set of explanatory variables; however there is no consent yet on the "best" model or approach. In this paper we propose a set of linear models with spatially weighted variables to forecast the change in unemployment. At this point though it is worth mentioning that the goal of this paper is to focus on short run forecasts only. We will discuss this issue later after presenting our main results.

A primary use of econometric models is for making out-of-sample forecast, however it is often the case that in spite of having good statistics (i.e. $R^{2}, \mathrm{t}$ statistics, MLE) in-sample models do not perform well for out-of-sample forecasts. We make our selection of the best model based on its out-of-sample forecasting properties, paying little or no attention to its in-sample properties.

This paper differs from related literature with regards to two main points. The first difference is the use of panel data rather than time series. Given the efficiency gains from pooling, as Baltagi and Griffin (1997) pointed out by observing the root mean square 
forecast error (RMSFE) of pooled data and comparing it with the RMSFE of individually heterogeneous models. We agree with the conclusions of Baltagi and Griffin (1997) that the forecast of the pooled data outperform that of the heterogeneous models. A similar conclusion using a different data set reached by Baltagi et al. (2000) shows once more that heterogeneous models for each individual produce estimates with inferior forecasting properties compared to that of pooled data. They also found that the efficiency gained in the forecast with the pooled data more than offset the bias due to individual heterogeneity.

The second difference with previous literature is the inclusion of spatially weighted variables. We construct a first order contiguity matrix to capture possible spillovers of neighboring states, something that as of our knowledge has not been done yet to forecast unemployment.

The next section makes some considerations about related literature and different approaches to unemployment forecasting. Section III explains the methodology as well as the data. Section IV shows the output and makes forecasting comparisons, and finally section $\mathrm{V}$ concludes.

\section{Related Literature}

The available literature for unemployment's forecasting is based in time series rather than panel data, however it is not conclusive on the behavior of unemployment. For example, Rothman's (1998) departure point is the asymmetric behavior of the postwar U.S. unemployment rate. This point has been stressed by Neftci (1984) who suggests that unemployment rate increases quickly in recessions but decreases slowly 
during expansions. Thus, the author concludes that it is reasonable that non-linear models may have a lower root mean squared error compared to linear models. Rothman used quarterly log-linear detrended unemployment rates for US and several other models in order to look for the lowest RMSE. His benchmark model was an AR(2) process that was compared to different non-linear models such as SETAR, ESTAR, EAR, GAR and BILINEAR. He concluded that the use of non-linear models can improve the forecast of the unemployment rate; however, this result is sensitive to the transformation of the unemployment rate series to stationary. He also found that EAR and GAR models present the best forecast. In a somewhat similar direction Montgomery et al. (1998) concludes that non- linear models have lower mean square forecast error, but the best model is still unknown since it depends on the frequency of the data.

The persistence of the unemployment rate has also been analyzed by Proietti (2003). His main finding is that hysteresis exists, given that linear models that include higher persistence perform better. He also found that the effects of hysteresis are not constant; therefore a non-linear forecast model outperforms a linear model, particularly in periods of slowly decreasing unemployment rate. However, it is worth mentioning that these gains are not particularly large.

Brown and Moshiri (2004) estimated and forecasted the unemployment rate for five countries using the artificial neural network (ANN) methodology and compared these results with linear and non-linear models. They suggest using non-linear models and ANN because unemployment over the business cycle is not symmetric. The authors conclude that ANN and non-linear models perform better than linear models and ANN performs as well as or even better than non-linear models. A similar conclusion is 
reached by Pelaez (2006) providing evidence of the usefulness of ANN to forecast unemployment.

The literature is extensive on unemployment forecasting, but in spite of the efforts to come up with a model or econometric methodology that forecasts unemployment efficiently, economists have yet to reach a consensus. This leaves the door wide open for further research and study in the area of unemployment forecasting.

\section{Data and Methodology}

The annual data for 48 contiguous states over the period 1978-2009 was obtained from the Bureau of Labor Statistics and Bureau of Economic Analysis. We do not consider Alaska and Hawaii. We used the growth in quantity indexes as a proxy for growth in real GDP.

As was mentioned earlier, one novelty in our research is that we use spatially weighted variables in addition to other variables. To do this we used a $48 \times 48$ matrix of first order queen spatial contiguity matrix, from now on called W. This matrix contains either one or zero depending on whether or not states share a common border. So the element $w_{i, j}$ is one if and only if state $i$ is a neighbor of state $j$, and is zero otherwise. There are two characteristics of this matrix: the main diagonal is composed only of zeros $^{11}$ and the entire matrix is normalized in such a way that the sum of each row adds up to one. Given that each row adds up to one all neighbors have the same spatial weight (i.e. if there are 5 neighbors each has a weight of 0.2 ). The next step is to multiply this

\footnotetext{
${ }^{11}$ The main diagonal is zero because a state cannot be a neighbor of itself.
} 
weight matrix by the variable that we are trying to weight. This will give us our first order contiguity spatially weighted variable.

Our method to generate the out-of-sample forecast will be based on a general model that can be expressed as:

\section{1. $\Delta u_{i, t}=\alpha_{i}+\beta X_{i, t-1}+\varepsilon_{i, t}$}

where $\Delta u_{i, t}$ is the change in unemployment in state $\mathrm{i}$ at time period $\mathrm{t}, \alpha_{i}$ represents an intercept for each state $\mathrm{i}$ in the case of panel data with fixed effects, however this intercept is common for the case of pooled OLS, $\beta$ represents a scalar (vector) of coefficient(s), $X_{i, t-1}$ represents a vector (matrix) with the lag of the independent variable(s), and $\varepsilon_{i, t}$ is a disturbance term. Our models include a combination of different explanatory variables such as change in log GDP, change in unemployment, spatially weighted change in log GDP and spatially weighted change in unemployment. For a more detailed explanation on the different models see table 4.1.

To generate our out-of-sample data we divided the total data $\mathrm{T}$ into an in-sample share made of the first $p$ observations and an out-of-sample share made of the last $r$ observations, where $p+r=T$. In this way we make our out-of-sample forecast for the first year based on the following equation:

$$
\text { 2. } \Delta \hat{u}_{i, p+1}=\hat{\alpha}_{i, p}+\hat{\beta}_{p} X_{i, p}
$$

where $\hat{\alpha}$ and $\hat{\beta}$ are the estimates of $\alpha$ and $\beta$, respectively, generated by regressing $\left\{\Delta u_{i, t}\right\}_{t=2}^{p}$ on a constant term and $\left\{X_{i, t}\right\}_{t=1}^{p-1}$. For the second out-of-sample forecast we have:

3. $\Delta \hat{u}_{i, p+2}=\hat{\alpha}_{i, p+1}+\hat{\beta}_{p+1} X_{i, p+1}$, 
where the coefficients are generated by regressing $\left\{\Delta u_{i, t}\right\}_{t=2}^{p+1}$ on a constant term and $\left\{X_{i, t}\right\}_{t=1}^{p}$. We continue to do this until the end of our out-of-sample period, and in doing so we try to simulate a real time forecast. Given that we are interested only in one year ahead forecast, we ended up with 48 different forecasts for each model for each out-ofsample year.

Finally we compute a loss function g[.] given by the difference of the forecasted value and the actual value. This loss function will helps us obtain the RMSFE or the MAFE.

\section{Forecast Properties}

There are different forecasting measurements that show how a model performs, however the most common is to look at the root mean square forecast error RMSFE defined as $\sqrt{\frac{\sum(y-\hat{y})^{2}}{N}}$, where $\mathrm{y}$ is the actual value of the dependent variable, $\hat{y}$ is the forecasted value and $\mathrm{N}$ is the total number of forecasts made. Another common measure is the mean absolute forecast error MAFE defined as $\frac{\sum|y-\hat{y}|}{N}$, where $y, \hat{y}$ and $\mathrm{N}$ have the same meaning as before.

Before analyzing the results, it is worth mentioning three things. Our first forecast is for the year 2003 and the last one for 2009. We made all the forecasts with and without state-fixed effects and we found the results to be similar. For this reason we only report the results without fixed effects ${ }^{12}$. Second, we only report the RMSFE, but the MAFE do

\footnotetext{
${ }^{12}$ Results with fixed effects are available upon request.
} 
not change our final conclusions. Finally, in addition to the thirteen different models, we also included another variable to control for national changes. In other words we have 26 different models, those shown in table 4.1, and the same models with the growth in national real GDP as another independent variable.

We based our model selection on the seven years average performance in order to maintain the parsimony of the forecast since we are not interested in any particular year but rather in the average performance.

We will first take a look at the case without controlling for national GDP. Table 4.2 exhibits the RMSFE for each of the seven year as well as the average. Based on these results we chose models four and ten, which each perform best in at least two years. For the case where we include national GDP as an independent variable (table 4.3) we chose models one and four. Once again model four performs best in two years. This should not be surprising since most time series forecasts on unemployment uses a lag set in unemployment as an independent variable; the novelty here is that the lag is spatially weighted. In other words, we are not using the state's specific lag on unemployment, but rather the weighted average of its neighbors.

Finally we test the null hypothesis that the RMSFE of the best two models are equal against the alternative that they are different. The test can be found in Clark and West (2007) ${ }^{13}$. This tests is asymptotically normal distributed, therefore, a value higher than 1.65 rejects the null hypothesis at a $5 \%$ confidence level, while a value of 1.28 rejects the null hypothesis at a $10 \%$ confidence level.

\footnotetext{
${ }^{13}$ We also run an extension of the Granger and Newbold (1986) suggested by Granger and Hyung (1999). There is a slight variation in the results, but overall the final conclusions remain the same.
} 
Table 4.4 shows the result of testing models four and ten (without controlling for changes in national GDP). We can observe that they perform equally well on a year-toyear basis. However looking at the average, model four seems to be the best. Recall that both models use a spatially weighted lag on unemployment.

Table 4.5 shows the results of testing the RMSFE of model one and four controlling for changes in national GDP. We observe that model four, in spite of having a better performance than model one in five out of the seven years; does not have a better performance on average. This may not seem intuitive, but the reason for this result is that the unemployment rate in years 2008 and 2009 was almost unpredictable due to the huge economic recession that followed the financial crisis. Thus, the square forecast error (SFE) for both years for all the models was incredibly high.

Finally in table 4.6 we compare model four without national GDP against its counterpart with national GDP. Even though they are pretty close to equal, on average, model four without controlling for the national GDP performs the best. All of these tests clearly indicate that in general model four performs better than its immediate follower ${ }^{14}$. None of the results seems to favor the models with more explanatory variables. This result goes hand in hand with Hsiao and Ki Wan (2010) findings that less but more crucial information seems to be better than exploiting all the information. Including more variables improves the in-sample properties but does not necessarily improve the out-ofsample properties of the estimators.

Our results show that GDP, own or spatially weighted; does not seem to be a good variable to forecast unemployment out of sample. The simple spatial AR(1) model

\footnotetext{
${ }^{14}$ We also compared model four with model eight which is the third best model. Our results show that model four performs better than model eight. Model eight also has spatially weighted unemployment which seems to be the crucial variable.
} 
outperform the other more complex models. Similar results have been documented in the time series context, Nelson (1972) showed that the out-of-sample forecast error generated from an ARIMA model were smaller than those generated by a more elaborate simultaneous system of equations (known as the FRB-MIT-PENN model) when explaining GDP, unemployment rate and interest rate. Meese and Rogoff (1983) reached a similar conclusion when forecasting exchange rate; showing that a simple random walk model performs better than all the structural models available at the time.

Overall the macro models that explicitly account for the historical evolution of the variables have superior forecasting performance. Our results illustrate the need to model the geographical context of regional macro variables for effective forecasting.

\section{Conclusions}

As we mentioned at the beginning, in spite of the advances in econometric techniques and the use of different data sets and explanatory variables to forecast unemployment, there is still a debate on which is the "best" model or technique to be used. However we present evidence that spatially weighted unemployment may improve forecasting performance of the unemployment rate.

In this paper we showed that the best models to forecast state-level unemployment rates are those that have spatially weighted unemployment as an explanatory variable. This may be explained by the characteristics of the U.S. labor market, which is homogeneous, without language barriers, and with very low migration frictions. On top of this, several states have a common labor market (Metropolitan 
Statistical Area) which makes their state-specific unemployment more dependent on neighboring conditions.

We also showed evidence that including more variables does not necessarily improve the out-of-sample forecasting properties of our models. In other words, our results favor parsimony. 
Table 4.1: Models without national GDP as an independent variable

\begin{tabular}{|c|c|}
\hline Number & Model \\
\hline 1 & $\Delta u_{i, t}=\alpha+\beta_{1} \Delta g d p_{i, t-1}$ \\
\hline 2 & $\Delta u_{i, t}=\alpha+\beta_{1} \Delta g d p_{i, t-1}+\beta_{2} \Delta u_{i, t-1}$ \\
\hline 3 & $\Delta u_{i, t}=\alpha+\beta_{1} \Delta u_{i, t-1}$ \\
\hline 4 & $\Delta u_{i, t}=\alpha+\beta_{1} \sum W_{i, j} \Delta u_{i, t-1}$ \\
\hline 5 & $\Delta u_{i, t}=\alpha+\beta_{1} \Delta g d p_{i, t-1}+\beta_{2} \sum W_{i, j} \Delta g d p_{i, t-1}$ \\
\hline 6 & $\Delta u_{i, t}=\alpha+\beta_{1} \Delta g d p_{i, t-1}+\beta_{2} \Delta u_{i, t-1}+\beta_{3} \sum W_{i, j} \Delta g d p_{i, t-1}$ \\
\hline 7 & $\Delta u_{i, t}=\alpha+\beta_{1} \Delta u_{i, t-1}+\beta_{2} \sum W_{i, j} \Delta g d p_{i, t-1}$ \\
\hline 8 & $\Delta u_{i, t}=\alpha+\beta_{1} \Delta g d p_{i, t-1}+\beta_{2} \sum W_{i, j} \Delta u_{i, t-1}$ \\
\hline 9 & $\Delta u_{i, t}=\alpha+\beta_{1} \Delta g d p_{i, t-1}+\beta_{2} \Delta u_{i, t-1}+\beta_{3} \sum W_{i, j} \Delta u_{i, t-1}$ \\
\hline 10 & $\Delta u_{i, t}=\alpha+\beta_{1} \Delta u_{i, t-1}+\beta_{2} \sum W_{i, j} \Delta u_{i, t-1}$ \\
\hline 11 & $\Delta u_{i, t}=\alpha+\beta_{1} \Delta g d p_{i, t-1}+\beta_{2} \sum W_{i, j} \Delta u_{i, t-1}+\beta_{3} \sum W_{i, j} \Delta g d p_{i, t-1}$ \\
\hline 12 & $\Delta u_{i, t}=\alpha+\beta_{1} \Delta g d p_{i, t-1}+\beta_{2} \Delta u_{i, t-1}+\beta_{3} \sum W_{i, j} \Delta u_{i, t-1}+\beta_{4} \sum W_{i, j} \Delta g d p_{i, t-1}$ \\
\hline 13 & $\Delta u_{i, t}=\alpha+\beta_{1} \Delta u_{i, t-1}+\beta_{2} \sum W_{i, j} \Delta u_{i, t-1}+\beta_{3} \sum W_{i, j} \Delta g d p_{i, t-1}$ \\
\hline
\end{tabular}

Note: $\Delta u_{i, t}$ is the change in unemployment rate at time $\mathrm{t}$ for state $\mathrm{i}, \Delta g d p_{i, t-1}$ is the change in log GDP for state $\mathrm{i}$ at time $\mathrm{t}-1, \sum W_{i, j} \Delta u_{i, t-1}$ is the spatially weighted change in unemployment rate for state $\mathrm{i}$ at time $\mathrm{t}-1$, and $\sum W_{i, j} \Delta g d p_{i, t-1}$ stands for the spatially weighted change in log GDP for state i at time t-1. For fixed effects the models are the same with the only difference that $\alpha$ becomes $\alpha_{i}$, indicating that each state has its own intercept rather than a common intercept. Additionally we run the same thirteen models with an extra independent variable $\Delta G D P_{t-1}$. This represents the change in log GDP for the United States at time $\mathrm{t}-1$. 
Table 4.2: Root mean square forecast error without controlling for national GDP

\begin{tabular}{|c|c|c|c|c|c|c|c|c|}
\hline Model & $\mathbf{2 0 0 3}$ & $\mathbf{2 0 0 4}$ & $\mathbf{2 0 0 5}$ & $\mathbf{2 0 0 6}$ & $\mathbf{2 0 0 7}$ & $\mathbf{2 0 0 8}$ & $\mathbf{2 0 0 9}$ & Average \\
\hline $\mathbf{1}$ & 0.3771 & $\mathbf{0 . 5 7 0 5}$ & 0.5289 & 0.6556 & 0.3189 & 1.1757 & 3.1543 & 0.9687 \\
\hline $\mathbf{2}$ & 0.3411 & 0.5918 & 0.4925 & 0.6382 & 0.3289 & 1.2204 & 2.9510 & 0.9377 \\
\hline $\mathbf{3}$ & 0.3383 & 0.5953 & 0.4898 & 0.6388 & 0.3186 & 1.2118 & 2.9498 & 0.9346 \\
\hline $\mathbf{4}^{*}$ & $\mathbf{0 . 3 1 9 5}$ & 0.6046 & 0.4885 & 0.5943 & $\mathbf{0 . 3 0 0 1}$ & 1.2271 & 2.9129 & $\mathbf{0 . 9 2 1 0}$ \\
\hline $\mathbf{5}$ & 0.3530 & 0.5851 & 0.5194 & 0.6665 & 0.3331 & $\mathbf{1 . 1 6 0 1}$ & 3.0883 & 0.9579 \\
\hline $\mathbf{6}$ & 0.3399 & 0.5937 & 0.4928 & 0.6395 & 0.3292 & 1.2176 & 2.9451 & 0.9368 \\
\hline $\mathbf{7}$ & 0.3385 & 0.5953 & 0.4899 & 0.6385 & 0.3194 & 1.2130 & 2.9446 & 0.9342 \\
\hline $\mathbf{8}$ & 0.3220 & 0.6020 & 0.4910 & 0.5901 & 0.3074 & 1.2385 & 2.9141 & 0.9236 \\
\hline $\mathbf{9}$ & 0.3318 & 0.5986 & 0.4876 & 0.6062 & 0.3181 & 1.2367 & 2.9036 & 0.9261 \\
\hline $\mathbf{1 0} * *$ & 0.3269 & 0.6034 & $\mathbf{0 . 4 8 3 8}$ & 0.6103 & 0.3030 & 1.2201 & $\mathbf{2 . 9 0 1 2}$ & 0.9212 \\
\hline $\mathbf{1 1}$ & 0.3229 & 0.6000 & 0.4911 & $\mathbf{0 . 5 8 5 3}$ & 0.3101 & 1.2467 & 2.9148 & 0.9244 \\
\hline $\mathbf{1 2}$ & 0.3326 & 0.5967 & 0.4873 & 0.6015 & 0.3195 & 1.2451 & 2.9044 & 0.9267 \\
\hline $\mathbf{1 3}$ & 0.3312 & 0.5981 & 0.4853 & 0.6004 & 0.3129 & 1.2411 & 2.9036 & 0.9247 \\
\hline
\end{tabular}

Note: The forecast is for one period ahead, and an average for the 7 years. The star above the model number represents the best model based on the average performance. One star is the best model, two stars is the second best. Numbers in bold are the best forecast. 
Table 4.3: Root mean square forecast error controlling for national GDP

\begin{tabular}{|c|c|c|c|c|c|c|c|c|}
\hline Model & $\mathbf{2 0 0 3}$ & $\mathbf{2 0 0 4}$ & $\mathbf{2 0 0 5}$ & $\mathbf{2 0 0 6}$ & $\mathbf{2 0 0 7}$ & $\mathbf{2 0 0 8}$ & $\mathbf{2 0 0 9}$ & Average \\
\hline $\mathbf{1}$ & 0.3386 & 0.6204 & 0.5256 & 0.6590 & 0.3198 & $\mathbf{1 . 1 1 6 8}$ & 2.9281 & 0.9297 \\
\hline $\mathbf{2}$ & 0.3410 & 0.5927 & 0.4919 & 0.6378 & 0.3303 & 1.2245 & $\mathbf{2 . 9 2 2 1}$ & 0.9343 \\
\hline $\mathbf{3}$ & 0.3389 & 0.5931 & 0.4889 & 0.6380 & 0.3229 & 1.2217 & 2.9248 & 0.9326 \\
\hline $\mathbf{4}$ & $\mathbf{0 . 3 2 0 9}$ & 0.5857 & 0.4827 & 0.5767 & $\mathbf{0 . 3 1 9 6}$ & 1.2846 & 2.9341 & $\mathbf{0 . 9 2 9 2}$ \\
\hline $\mathbf{5}$ & 0.3365 & 0.6177 & 0.5216 & 0.6625 & 0.3250 & 1.1218 & 2.9388 & 0.9319 \\
\hline $\mathbf{6}$ & 0.3401 & 0.5919 & 0.4915 & 0.6395 & 0.3322 & 1.2250 & 2.9262 & 0.9352 \\
\hline $\mathbf{7}$ & 0.3387 & 0.5929 & 0.4885 & 0.6385 & 0.3227 & 1.2215 & 2.9270 & 0.9328 \\
\hline $\mathbf{8}$ & 0.3221 & 0.5857 & 0.4840 & 0.5758 & 0.3220 & 1.2863 & 2.9337 & 0.9299 \\
\hline $\mathbf{9}$ & 0.3315 & $\mathbf{0 . 5 8 0 0}$ & 0.4796 & 0.5913 & 0.3343 & 1.2889 & 2.9280 & 0.9334 \\
\hline $\mathbf{1 0}$ & 0.3285 & 0.5806 & $\mathbf{0 . 4 7 6 6}$ & 0.5919 & 0.3264 & 1.2849 & 2.9311 & 0.9314 \\
\hline $\mathbf{1 1}$ & 0.3224 & 0.5859 & 0.4843 & $\mathbf{0 . 5 7 5 1}$ & 0.3225 & 1.2867 & 2.9322 & 0.9298 \\
\hline $\mathbf{1 2}$ & 0.3317 & 0.5801 & 0.4796 & 0.5910 & 0.3345 & 1.2891 & 2.9272 & 0.9333 \\
\hline $\mathbf{1 3}$ & 0.3302 & 0.5808 & 0.4778 & 0.5898 & 0.3291 & 1.2869 & 2.9277 & 0.9317 \\
\hline
\end{tabular}

Note: The forecast is for one period ahead, and an average for the 7 years. The star above the model number represents the best model based on the average performance. One star is the best model, two stars is the second best. Numbers in bold are the best forecast. 
Table 4.4: Clark-West test for models four and one without controlling for national GDP

\begin{tabular}{|c|c|c|c|}
\hline Year & C-W test & Reject null & Best Model \\
\hline $\mathbf{2 0 0 3}$ & -0.20 & No & - \\
\hline $\mathbf{2 0 0 4}$ & 0.44 & No & - \\
\hline $\mathbf{2 0 0 5}$ & 1.06 & No & - \\
\hline $\mathbf{2 0 0 6}$ & -0.63 & No & - \\
\hline $\mathbf{2 0 0 7}$ & 0.48 & No & - \\
\hline $\mathbf{2 0 0 8}$ & 1.12 & No & - \\
\hline $\mathbf{2 0 0 9}$ & 1.24 & No & - \\
\hline Average & $1.34 * *$ & Yes & 4 \\
\hline
\end{tabular}

Note: The null hypothesis is that both RMSFE are equal for models 4 and 1 . One star means that we reject the null at a 5\% level, two stars means that we reject the null at a $10 \%$ level. 
Table 4.5: Clark-West test for models four and ten controlling for national GDP

\begin{tabular}{|c|c|c|c|}
\hline Year & C-W test & Reject null & Best Model \\
\hline $\mathbf{2 0 0 3}$ & $2.49^{*}$ & Yes & 4 \\
\hline $\mathbf{2 0 0 4}$ & $3.83^{*}$ & Yes & 4 \\
\hline $\mathbf{2 0 0 5}$ & $2.91^{*}$ & Yes & 4 \\
\hline $\mathbf{2 0 0 6}$ & $6.12^{*}$ & Yes & 4 \\
\hline $\mathbf{2 0 0 7}$ & $2.54^{*}$ & Yes & 4 \\
\hline $\mathbf{2 0 0 8}$ & $-9.69^{*}$ & Yes & 1 \\
\hline $\mathbf{2 0 0 9}$ & -0.14 & No & - \\
\hline Average & -0.15 & No & - \\
\hline
\end{tabular}

Note: The null hypothesis is that both RMSFE are equal for models 1 and 4 . One star means that we reject the null at a $5 \%$ level, two stars means that we reject the null at a $10 \%$ level. 
Table 4.6: Clark-West test for models four with and without controlling for national GDP

\begin{tabular}{|c|c|c|c|}
\hline Year & C-W test & Reject null & Best Model \\
\hline $\mathbf{2 0 0 3}$ & -0.25 & No & - \\
\hline $\mathbf{2 0 0 4}$ & $7.01^{*}$ & Yes & $4 \mathrm{n}$ \\
\hline $\mathbf{2 0 0 5}$ & $1.78^{*}$ & Yes & $4 \mathrm{n}$ \\
\hline $\mathbf{2 0 0 6}$ & $5.39^{*}$ & Yes & $4 \mathrm{n}$ \\
\hline $\mathbf{2 0 0 7}$ & $-1.36^{* *}$ & Yes & 4 \\
\hline $\mathbf{2 0 0 8}$ & $-11.73^{*}$ & Yes & 4 \\
\hline $\mathbf{2 0 0 9}$ & $-14.82^{*}$ & Yes & 4 \\
\hline Average & $-7.36^{*}$ & Yes & 4 \\
\hline
\end{tabular}

Note: The null hypothesis is that both RMSFE are equal for models 4 controlling and without controlling for national GDP. The $\mathrm{n}$ next to the 4 means that the best model is the one controlling for national GDP. One star means that we reject the null at a 5\% level, two stars means that we reject the null at a $10 \%$ level. 


\section{Bibliography}

Adanu, Kwami; "A Cross-Province Comparison of Okun's Coefficient for Canada" Applied Economics, March 2005, vol. 37, issue 5, pp. 561-570.

Akaike, Hirotugu; "A new look at the statistical model identification" IEEE Transactions on Automatic Control, 1974,19(6), pp. 716-723.

Anselin Luc and Rey Sergio; "Perspectives on Spatial Data Analysis" Springer Heidelberg Dordrecht, 2010.

Arbia, Giuseppe; "Spatial Data Configuration is Statistical Analysis of Regional Economic and Related Problemse” Kluwer Academic Publisers 1988.

Arbia, Giuseppe; "Spatial Econometrics: Statistical Foundations and Applications to Regional Convergence” Springer-Verlag 2006.

Attfield. C. L. E. and B. Silverstone; "Okun's Coefficient: A Comment” Review of Economics and Statistics' 1997, 79, pp. 326-29.

Baltagi, Badi and Griffin, James "Pooled Estimators vs. Their Heterogeneous Counterparts in the Context of Dynamic Demand for Gasoline" Journal of Econometrics, (1997), vol. 77, pp. 303-327.

Baltagi Badi, Griffin James, Xoing Weiwen "To Pool or not to Pool: Homogeneous vs. Heterogeneous Estimators Applied to Cigarrete Demand" The Review of Economics and Statistics (2000), vol. 82, pp. 117-126.

Blackley, Paul; “The Measurement and Determination of Okun's Law: Evidence from State Economies" Journal of Macroeconomics, Fall 1991, vol. 43, no.4, pp. 641-656.

Blanchard Olivier, Katz Lawrence; "Regional Evolutions" Brookings Papers on Economic Activity, 1992, vol. 23, pp. 1-76. 
Brown Laura, Moshiri Saeed "Unemployment Variation over the Business Cycles: a Comparison of Forecasting Models" Journal of Forecasting, (2004), vol. 23, pp.497511.

Christopoulos, Dimitris; “The relationship between output and unemployment: Evidence from Greek regions" Papers in Regional Science, 2004, 83, pp. 611-620.

Clark, Todd and West Kenneth "Approximately Normal Tests for Equal Predictive Accuracy in Nested Models" Journal of Econometrics, (2007), vol. 138, pp.291-311.

Freeman, Donald; "Regional Tests of Okun's Law" International Advances in Economic Research, 2000, vol. 6, pp. 557-570.

Freeman, Donald.; "Panel tests of Okun's law for ten industrial countries" Economic Inquiry, 2001, 39, pp. 511-23.

Gabriel, Stuart. A., Shack-Marquez, Janice and William A. Wascher; "Does Migration Arbitrage Regional Labor Market Differentials?" Regional Science and Urban Economics, 1993, 78(2), pp. 211-233.

Gordon, Robert; "Unemployment and Potential Output in the 1980s" Brookings Papers on Economic Activity, 1984, no 2, pp. 537-64.

Gordon, Robert; “Okun's Law, Productivity Innovations, and Conundrums in Business Cycle Dating” American Economic Review: Papers \& Proceedings, 2010,100(2),pp. $11-15$.

Granger, Clive and Hyung Namwon; "Spurious Stochastics in a Short Time-Series Panel Data" Annales d'Economie et de Statistique, (1999), vol. 55-56.

Granger, Clive and Newbold P.; Forecasting Economic Time Series Academic Press (1986). 
Hsiao Cheng and and Ki Wan Shui; "Is there an optimal forecast combination?" Working paper, 2010

Kaufman, Roger; “An International Comparison of Okun's Law” Journal of Comparative Economics, 1988, vol. 12, pp. 182-203.

Knotek II, Edward S.; “How Useful is Okun's Law?" Economic Review, Federal Reserve Bank of Kansas City, 2007, 92(4), pp. 73-103.

Kosfeld, Reinhold and Christian Dreger; "Thresholds for employment and unemployment: A spatial analysis of German regional labour markets, 1992-2000" Papers in Regional Science, November 2006, vol. 85(4), pp. 523-542.

Lee, Jim; “The Robustness of Okun's Law: Evidence from OECD Countries” Journal of Macroeconomics, Spring 2000, 22(2), pp. 331-56.

LeSage, James and Matthew Dominguez; “The Importance of Modeling Spatial Spillovers in Public Choice Analysis" 2010, Public Choice, forthcoming.

LeSage, James and Pace Kelly; "Introduction to Spatial Econometrics" Taylor \& Francis Group, 2009.

LeSage, James and Pace Kelly; "The Biggest Myth in Spatial Econometrics" Working Paper, 2010.

Meese Richar and Rogoff Kenneth; "Empirical Exchange Rate Models of the Seventies: Do they fit out of Sample?" Journal of International Economics, 1983, Vol 14.

Molho, Ian; "Spatial Autocorrelation in British Uemployment" Journal of Regional Science, 1995, Vol. 35, No. 24, pp. 641-658.

Moosa, Imad; "A Cross-Country Comparison of Okun's Coefficient" Journal of Comparative Economics, 1997, no. 24, pp. 335-356. 
Montgomery Alan, Zarnowitz Victor, Tsay Ruey, Tiao George; "Forecasting the U.S. Unemployment Rate" Journal of the American Statistical Association, (1998), vol. 93, No 442, pp. 478-493.

Neely, Christopher J; “Okun's Law: Output and Unemployment” Economic Synopses, Federal Reserve Bank of St. Louis, 2010, no. 4.

Neftci, Salih; "Are Economic Time Series Asymmetric over the Business Cycle?" Journal of Political Economy, (1984), vol 92, pp.307-328.

Nelson, Charles; "The Prediction Performance of the FRB-MIT-PENN Model of the U.S. Economy’'American Economic Review, 1972, vol 72, No. 5, pp.902-917.

Okun, Arthur; "Potential GNP: Its Measurement and Significance" American Statistical Association, Proceedings of the Business and Economics Statistics Section, 1962.

Pelaez, Rolando; "Using Neural Nets to Forecast the Unemployment Rate" Business Economics, January (2006), pp. 37-44.

Prachowny, Martin; “Okun's Law: Theoretical Foundations and Revised Estimates" The Review of Economic and Statistics, May 1993, vol. 75, no. 2, pp. 331-336.

Rothman, Philip; "Forecasting Asymmetric Unemployment Rates" The Review of Economics and Statistics, (1998), vol. 80, pp. 164-168.

Schoeb, R. and David E. Wildasin; "Economic integration and labor market institutions: Worker mobility, earnings risk, and contract structure” Regional Science and Urban Economics, 2007, 37(2), pp. 141-164.

Tommaso, Proietti; "Forecasting the US Unemployment Rate" Computational Statistics \& Data Analysis, (2003), vol. 42, pp. 451-476.

Villeverde, Jose and Adolfo Maza; “The Robustness of Okun's Law in Spain, 19802004 Regional Evidence” Journal of Policy Modeling, 2009, 31, pp. 289-297. 
Weber, Christian; “Cyclical Output, Cyclical Unemployment, and Okun's Coefficient: A New Approach" Journal of Applied Econometrics, 1995, vol. 10, issue 4, pp. 433445.

Yazgan, Mustafa and Hakan Yilmazkuday; "Okun's Convergence within the U.S." Letters in Spatial and Resource Science, 2009, vol. 2, pp. 109-122. 


\section{Appendix}

\section{Derivation of Direct and Indirect Effects}

Starting from equation 6 in section II

$$
Y=\Psi+\Gamma+X \beta+W_{T} X \theta+W_{T} Y \rho+\varepsilon
$$

We can re-write (A.1) as

$$
\begin{aligned}
& \left(I_{N T}-\rho W_{T}\right) Y=\Psi+\Gamma+X \beta+W_{T} X \theta+\varepsilon \\
& Y=\left(I_{N T}-\rho W_{T}\right)^{-1}\left(\Psi+\Gamma+X \beta+W_{T} X \theta+\varepsilon\right)
\end{aligned}
$$

(A.1') $\quad Y=Z^{-1}\left(\Psi+\Gamma+X \beta+W_{T} X \theta+\varepsilon\right)$

where $Z^{-1}$ is a block of matrices of $\mathrm{N} \times \mathrm{N}$ with the inverse of $\left(I_{N T}-\rho W_{T}\right)$ in the main diagonal.

$$
Z_{N T \times N T}=\left[\begin{array}{cccc}
\left(I_{N}-\rho W\right) & 0_{N} & \ldots & 0_{N} \\
0_{N} & \left(I_{N}-\rho W\right) & \ldots & 0_{N} \\
\vdots & \vdots & \ddots & \vdots \\
0_{N} & 0_{N} & \ldots & \left(I_{N}-\rho W\right)
\end{array}\right]
$$

To show the marginal-effect estimates, we redefine (A.1') as

$$
Y=\sum_{k=1}^{K} S_{k}(W) X_{k}+Z^{-1}(\Psi+\Gamma+\varepsilon)
$$

$$
S_{k}(W)=Z^{-1}\left(I_{N T} \beta_{k}+W_{T} \theta_{k}\right)
$$




$$
Z^{-1}=\left(I_{N}-\rho W\right)^{-1}=\left(I_{N}+\rho W+\rho^{2} W^{2}+\rho^{3} W^{3}+\ldots+\rho^{\infty} W^{\infty}\right)
$$

where the sub index $\mathrm{k}$ denotes the independent variable $\mathrm{k}$ out of a set of $\mathrm{K}$ independent variables, put another way $X_{k}$ is the $k^{\text {th }}$ column of the $N T \times K$ matrix of independent variables. For any period $t$, the marginal effects on $\mathrm{Y}$ given a change in $\mathrm{X}$ is defined as

$$
\frac{\partial y_{t}}{\partial x_{t}^{k}}=S_{k}^{t}(W)=\left(I_{N}-\rho W\right)^{-1}\left(I_{N} \beta_{k}+W \theta_{k}\right)
$$

It is easy to see that (A.6) is an $\mathrm{N} \times \mathrm{N}$ matrix that shows the change in each region's dependent variable as a result of a change in the own region as well as other region's change of the independent variable; or in matrix form

$$
S_{k}^{t}(W)_{N \times N}=\left[\begin{array}{cccc}
\frac{\partial y_{1, t}}{\partial x_{1, t}^{k}} & \frac{\partial y_{1, t}}{\partial x_{2, t}^{k}} & \ldots & \frac{\partial y_{1, t}}{\partial x_{N, t}^{k}} \\
\frac{\partial y_{2, t}}{\partial x_{1, t}^{k}} & \frac{\partial y_{2, t}}{\partial x_{2, t}^{k}} & \ldots & \frac{\partial y_{2, t}}{\partial x_{N, t}^{k}} \\
\vdots & \vdots & \ddots & \vdots \\
\frac{\partial y_{N, t}}{\partial x_{1, t}^{k}} & \cdots & \ldots & \frac{\partial y_{N, t}}{\partial x_{N, t}^{k}}
\end{array}\right]
$$

We can observe that the main diagonal in (A.7) is $S_{k}^{t}(W)_{i i}=\frac{\partial y_{i, t}}{\partial x_{i, t}^{k}}$. The set of all this partial derivatives are averaged to obtain a measured of the direct effect. In a similar fashion $S_{k}^{t}(W)_{i j}=\frac{\partial y_{i, t}}{\partial x_{j, t}^{k}}$ are averaged to obtain the indirect effects. Adding both we obtain the total effect. 